\title{
Influence of Post-treatment on the Microstructural and Tribomechanical Properties of Suspension Thermally Sprayed WC-12 wt\% Co Nanocomposite Coatings
}

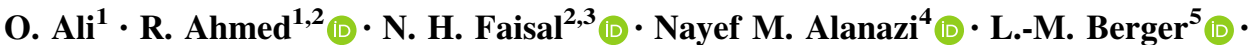 \\ A. Kaiser ${ }^{5}$ (D) F.-L. Toma ${ }^{6}$ (D) E. K. Polychroniadis ${ }^{7}$ - M. Sall ${ }^{7}$ (D) - Y. O. Elakwah ${ }^{2}$. \\ M. F. A. Goosen ${ }^{8}$
}

Received: 18 December 2016/ Accepted: 4 January 2017 / Published online: 19 January 2017

(c) The Author(s) 2017. This article is published with open access at Springerlink.com

\begin{abstract}
The potential to improve the tribomechanical performance of HVOF-sprayed WC-12Co coatings was studied by using aqueous WC-12Co suspensions as feedstock. Both as-sprayed and hot-isostatic-pressed (HIPed) coatings were studied. Mathematical models of wear rate based on the structure property relationships, even for the conventionally sprayed WC-Co hardmetal coatings, are at best based on the semiempirical approach. This paper aims to develop these semiempirical mathematical models for suspension sprayed nanocomposite coatings in as-sprayed and heat-treated (HIPed) conditions. Microstructural evaluations included transmission electron microscopy, X-ray diffraction and scanning electron microscopy equipped with energy-dispersive X-ray spectroscopy. The nanohardness
\end{abstract}

R. Ahmed

R.Ahmed@hw.ac.uk

1 School of Engineering and Physical Sciences, Heriot-Watt University, Edinburgh EH14 4AS, UK

2 College of Engineering, Alfaisal University, P.O. Box 50927, Riyadh 11533, Saudi Arabia

3 School of Engineering, Robert Gordon University, Garthdee Road, Aberdeen AB10 7GJ, UK

4 Materials Performance Unit, Research and Development Centre, Saudi Aramco, Dhahran 31311, Saudi Arabia

5 Fraunhofer IKTS, Fraunhofer Institute for Ceramic Technologies and Systems, Winterbergstrasse 28, 01277 Dresden, Germany

6 Fraunhofer IWS, Fraunhofer Institute for Material and Beam Technology, Winterbergstrasse 28, 01277 Dresden, Germany

7 Department of Physics, Aristotle University of Thessaloniki, 54124 Thessaloniki, Greece

8 Office of Research and Graduate Studies, Alfaisal University, P.O. Box 50927, Riyadh 11533, Saudi Arabia and modulus of the coated specimens were investigated using a diamond Berkovich nanoindenter. Sliding wear tests were conducted using a ball-on-flat test rig. Results indicated that the HIPing post-treatment resulted in crystallization of amorphous coating phases and increase in elastic modulus and hardness. Influence of these changes in the wear mechanisms and wear rate is discussed. Results are also compared with conventionally sprayed high-velocity oxy-fuel hardmetal WC-Co coatings.

Keywords Nanostructured coating - Sliding wear - WC12Co coating $\cdot$ Suspension spraying $\cdot$ Hot isostatic pressuring (HIPing) $\cdot$ Microstructure $\cdot$ Phase composition . Wear mechanism · Tribology

\section{Introduction}

According to the state of the art, wear-resistant WC-Co coatings are predominantly obtained by high-velocity oxyfuel spraying (HVOF) from conventional feedstock powders. During spraying of WC-Co powders, significant changes in the chemical and phase compositions can occur [1]. The past two decades have seen extensive research in optimizing the feedstock powder characteristics, process parameters and post-treatments of wear-resistant hardmetal coatings [2-14]. Most research, however, has related to the coatings sprayed from agglomerated and sintered powders, with the typical particle size ranging from 10 to $50 \mu \mathrm{m}$ and $\mathrm{WC}$ grain size ranging from 0.8 to $3.5 \mu \mathrm{m}$ [2-7]. Optimization of these coatings has resulted in coating microstructures with negligible porosity, high fracture toughness and minimization of secondary carbide phases [2-10, 15-18].

Nanocomposite hardmetal coatings are still undergoing research and development. These coatings have the 
potential to provide further improvement in their tribomechanical performance. Previous researchers have used conventional thermal spray systems to deposit coatings from nanostructured WC-Co feedstocks [9, 10, 19-21]. In these previous investigations, agglomerated and sintered nanosized particles have been used for the deposition of nanostructured thermal spray coatings, generally resulting in a predominantly bimodal coating structure, where the coating architecture exhibits micrometer-sized zones with nanometer-sized structure [19]. Suspension spraying is currently the only viable route capable of depositing nanocomposite coatings directly from nanosized feedstock powder. However, thermal spraying of these nanocomposite hardmetal coatings, especially WC-Co, is technologically challenging. By this reason, so far only few studies on this topic are published in the literature [22-24].

The first investigation of suspension sprayed WC-Co coatings was done by Oberste Berghaus et al. [24]. They conducted a comprehensive study in order to develop WC$12 \%$ Co nanocomposite coatings by suspension spraying using a commercial atmospheric plasma spray process (APS) (AXIAL III, Northwest Mettech Corp., Canada) of an ethanol-based suspension with $20 \mathrm{wt} \%$ solid concentration and an internal injector. They indicated that coatings with low porosity were produced which showed a maximum hardness of about 700 HV0.3. These coatings also showed a pronounced amorphous "hump" in the XRD pattern. When a nanostructured agglomerated and sintered powder in an ethanol/ethylene glycol suspension was used, the crystallinity of the coating and the hardness (about 780 HV0.3) increased. In our previous studies, nanostructured suspension sprayed WC-Co HVOF coatings were successfully produced from aqueous suspensions of nanocomposite particles [22, 23]. Moreover, despite a high carbon loss during spraying, these S-HVOF coatings had hardness values comparable to those of conventional HVOF WC-Co coatings.

Thermal treatment is one of the most important posttreatment methods for thermal spray coatings [1]. Main effect can be from a shift of the phase composition from the as-deposited non-equilibrium toward the equilibrium state, but also change in the residual stress state, densification by sintering and the cross-diffusion of elements between the coating and the substrate. The extent of these changes is dependent upon the composition and microstructure of the starting powder and deposited coating. Due to the high oxidation rate above $600{ }^{\circ} \mathrm{C}$, the thermal treatment of $\mathrm{WC}-$ Co coatings has to be carried out in inert atmosphere or vacuum. Microstructural effects appearing in a WC-17\% Co coating during thermal analyses for determination of the thermophysical properties have been described previously [25]. These microstructural changes were also studied by mechanical spectroscopy [26]. Depending on the chemical composition of the as-sprayed coating and heat treatment conditions, a replacement of the amorphous phase, metallic $\mathrm{W}$, as well as the non-equilibrium phase $\mathrm{W}_{2} \mathrm{C}$ by the formation of $\eta$-phases was observed, e.g., [27-31].

In our previous research, it was shown that the heat treatment of HVOF-sprayed WC-based coatings, i.e., WCCo and WC-NiCrBSi coatings, can be effectively applied to crystallize amorphous phases and hence further improve the tribomechanical performance of coatings [15-17, 32, 33]. A better bonding resulting from the heat treatment at the intersplat and interlayer levels and changes in through thickness profile of residual stresses was predominantly responsible for the improvement in fracture toughness, hardness and elastic modulus [34, 35]. As a result, sliding wear and rolling contact fatigue performance also improved. The extent of these improvements was dependent upon the selection of time and temperature used for vacuum heat treatment and the additional parameter of pressure in HIPing. It is also possible to control the diffusion layer at the coating substrate interface by varying the heat treatment parameters.

WC-Co coatings are highly suitable for service under dry sliding conditions, preferably at room temperature, as mentioned above. Studies have been performed in pairs of different materials for the counterbody, such pairs can show total wear rates (sum of wear rates of the coating and the counterbody) of less than $10^{-6} \mathrm{~mm}^{3} / \mathrm{Nm}$, i.e., comparable to values typically measured under mixed/boundary conditions [36, 37].

The emphasis in the current paper is to consider the influence of a post-treatment of suspension sprayed S-HVOF WC-12Co coatings via hot isostatic pressing (HIPing) on the tribomechanical performance against the previously reported as-sprayed S-HVOF coatings [22, 23]. In order to support the interpretation of the changes, the influence of carbon loss on the expected equilibrium phases was evaluated by thermodynamic calculations. This paper also aims to develop semiempirical mathematical models of wear rate based on structure property relationships for suspension sprayed nanocomposite coatings in as-sprayed and heat-treated (HIPed) conditions. Microstructural and tribomechanical investigations included scanning electron microscopy (SEM), energy-dispersive X-ray spectroscopy (EDX), transmission electron microscopy (TEM), X-ray diffractometry (XRD), nanohardness and sliding wear evaluations.

\section{Experimental}

\subsection{Coating Deposition and Post-treatment}

Coatings were prepared with earlier optimized parameter sets by S-HVOF spraying using two types of fine WC- 
12 wt\%Co powders (Powder 1 (P1) Dong Yang (HK) Int'1 Group Limited) [22] and Powder 2 (P2) Fujimi Corp., Japan - DTS W653-20/5 [23] to produce the aqueous suspensions with $25 \mathrm{wt} \%$ solid content. The carbon and oxygen content of both powders are given in Table 1. Both powders underwent a milling process in a planetary ball mill to decrease the particle size before suspension preparation. S-HVOF spraying was conducted using a modified HVOF (TopGun, GTV mbH, Luckenbach, Germany) spray process using ethene as the fuel gas. The suspensions were fed from an automated pressure vessels feeding system developed at Fraunhofer IWS with a feed rate of 25-30 ml/ min and axially injected in the combustion chamber of the TopGun. The deposition efficiency was slightly lower than that obtained from conventional HVOF spray process. In order to compare performance against standard HVOF coatings, HVOF-JK (Jet Kote) coating was deposited using WC-12 wt\%Co agglomerated and sintered powder using industrially optimized coating process parameters [38, 39]. All coatings were deposited on AISI440C steel disks of $31 \mathrm{~mm}$ diameter and $6 \mathrm{~mm}$ thickness. An overview of coatings is given in Table 2.

All S-HVOF coatings were heat-treated by hot isostatic pressing (HIPing) at $920{ }^{\circ} \mathrm{C}$ for $2 \mathrm{~h}$ at $103 \mathrm{MPa}$ in argon atmosphere in order to investigate the transformation of the amorphous constituents into a crystalline state. The heating and cooling rate during HIPing were of about 8.7-9.0 and 5.8-6.9 K/min, respectively. Samples are normally encapsulated prior to HIPing to prevent surface cracking which can occur with high temperatures and pressures. However, this restricts the complexity in shape for the HIPed components and increases the cost of HIPing. HIPing of $\mathrm{S}$-HVOF coatings was therefore conducted in unencapsulated conditions.

During spraying of WC-Co suspensions by HVOF, a high carbon loss was observed [22, 23]. With the HIPing treatment, the coating is expected to be transformed from the strongly non-equilibrium as-sprayed state into a state shifted toward equilibrium. For a better interpretation of the changes in material composition during spraying and the heat treatment, the phase compositions appearing with progressive carbon loss in thermodynamic equilibrium conditions for WC-12\% Co composition were calculated.

Thermochemical calculations have been performed with the Software FactSage $(C)$ of the companies Thermfact/ CRCT (Montreal, Canada) and GTT-Technologies

Table 1 Carbon and oxygen contents of the feedstock powders

\begin{tabular}{lll}
\hline Powder & Carbon content (mass\%) & Oxygen content (mass\%) \\
\hline P1 & 5.99 & 0.37 \\
P2 & 5.59 & 0.05 \\
\hline
\end{tabular}

(Aachen, Germany) in version 6.4. FactSage $($ C is a software to predict the stable chemical equilibrium state based on the principle of minimization of Gibbs energy combined with comprehensive thermochemical databases. In the present case, thermochemical calculations have been performed with the "Phase Diagram" module to calculate isothermal sections through the ternary $\mathrm{W}-\mathrm{Co}-\mathrm{C}$ system to describe the stable phase equilibrium and with the "Equilibrium" module to calculate the stable equilibrium state with varying compositions. The used thermodynamic dataset is substantially based on published thermodynamic data from the literature. For these calculations, it was assumed that individual oxide phases do not exist, and all oxygen is contained in the carbide or metallic phases.

\subsection{Microstructural Evaluations}

In order to ascertain the changes in chemical and phase compositions during the spray process, the starting powders and also the coating segments detached from the substrate were analyzed for their total carbon content by the combustion method (CS 230, LECO Corporation, St. Joseph, MI, USA) and oxygen content by the carrier gas hot extraction (TCH 600, LECO Corporation, St. Joseph, MI, USA). The microstructure of the powders and coatings was observed via SEM by secondary electron (SE) and backscattered electron (BE) imaging equipped with energydispersive EDX. Observations were made on the polished cross sections. The phase compositions of the coatings were determined via XRD with $\mathrm{Cu}-\mathrm{K} \alpha$ radiation (wavelength $0.15406 \mathrm{~nm}$ ) including Rietveld analysis. TEM observations of the samples were made on the coating surface. The samples were prepared under plane view configuration. They were thinned down to less than $50 \mu \mathrm{m}$ by mechanical polishing. The electron transparency was achieved by ion milling at $5 \mathrm{kV}$ using the GATAN precision ion polisher system (PIPS) at an incidence angle of $5^{\circ}$. The observations were performed on a JEOL 2000 TEM operating at $200 \mathrm{kV}$.

\subsection{Hardness and Modulus Measurements}

Vickers microhardness of S-HVOF and conventional HVOF coatings was determined on polished cross sections by five measurements at a load of $2.94 \mathrm{~N}(300 \mathrm{~g})$. Nanoindentation testing which included hardness and elastic modulus measurements was performed by a calibrated nanoindentation system (NanoTest $^{\mathrm{TM}}$-Micro Materials Limited, UK) equipped with a standard Berkovich nanoindenter. Measurements were taken at room temperature $\left(\sim 23{ }^{\circ} \mathrm{C}\right)$ in load control mode at a load of $50 \mathrm{mN}$.

The indentation procedures were programmed as three segments of trapezoidal shape with loading, hold and 
Table 2 Coating thickness and vickers hardness values for S-HVOF and HVOF-JK coatings

\begin{tabular}{lllllrll}
\hline Sample & Spray process & Feedstock & $\begin{array}{l}\text { State of } \\
\text { coating }\end{array}$ & $\begin{array}{l}\text { Coating thickness } \\
(\mu \mathrm{m})\end{array}$ & HV0.3 & $\begin{array}{l}\text { Carbon content } \\
(\mathrm{mass} \%)\end{array}$ & $\begin{array}{l}\text { Oxygen content } \\
(\mathrm{mass} \%)\end{array}$ \\
\hline P1C & S-HVOF & P1 (nano, milled) & As sprayed & 210 & $942 \pm 15$ & 2.0 & 1.8 \\
P1C-HIP & S-HVOF & P1 (nano, milled) & HIPed & 210 & $1201 \pm 74$ & - & - \\
P2C & S-HVOF & P2 (a\&s, milled) & As sprayed & 140 & $998 \pm 73$ & 1.2 & 1.0 \\
P2C-HIP & S-HVOF & P2 (a\&s, milled) & HIPed & 140 & $1130 \pm 140$ & - & - \\
P3C & HVOF & P3 (a\&s) & As sprayed & 330 & $924 \pm 127$ & - & - \\
\hline
\end{tabular}

unloading segments. A set of six equally spaced measurement sets were taken on the sample cross sections at various distances from the coating substrate interface. Each measurement set contained five measurements, and averaged values of each measurement set are reported in the results section. The force-displacement $(P-h)$ profiles were analyzed using the area function for the Berkovich indenter, which was determined by indentations into fused silica with an elastic modulus of $69.9 \mathrm{GPa}$. The raw data $(P-$ $h$ profile) were employed to evaluate hardness and reduced elastic modulus $\left(E_{\mathrm{r}}\right)$ using the Oliver and Pharr method [40]. The modulus and Poisson's ratio of the diamond indenter were taken as 1140 and $0.07 \mathrm{GPa}$, respectively.

\subsection{Sliding Wear Investigations}

The dry sliding wear resistance was examined via ball-onflat tests in reciprocating mode. These tests were conducted at room temperature on a bench-mounted wear test machine (BLR2000 M; Bud Labs, USA). The ball-on-flat tests were conducted using three different ball materials: (1) AISI 440C steel (12.7-mm ball diameter), (2) HIPed $\mathrm{Si}_{3} \mathrm{~N}_{4}$ (12.7$\mathrm{mm}$ ball diameter) and (3) sintered WC-6\% Co (9.5-mm ball diameter) against the coated disk sample under a normal load of $25 \mathrm{~N}$. The test conditions were similar to ASTM G133-02 (procedure A). The sliding distance of $500 \mathrm{~m}$ was used for all test couples. The average surface roughness $\left(R_{\mathrm{q}}\right)$ of the disk samples after finishing by grinding and polishing was $0.05 \mu \mathrm{m}$. During the test, the disk experienced reciprocating sliding motion at an oscillating frequency of $2.0 \mathrm{~Hz}$, with a stroke length of $10 \mathrm{~mm}$. Five tests were conducted for each test couple. Wear volume loss of the coating was computed from the length of the stroke and the average cross-sectional area of the wear grooves, which was measured via the interferometer (Zygo New View). The corresponding ball volume loss was calculated using the following geometrical relations:

$V=\frac{\pi H^{2}}{3}(3 R-H)$

where $H=R-\sqrt[2]{R^{2}-r^{2}}$ and $R, r$ are the ball radius and ball-wear-scar radius, respectively. Optical microscopy was used for a precise measurement of the ball-wear-scar radius. This methodology is consistent with the ball volume loss calculations adapted in ASTM G99 and ASTM G13302. The wear scars and debris after the sliding wear tests were examined by optical microscopy and SEM. Friction coefficient was evaluated using a tension-compression load cell mounted on the sliding wear rig. Averaged friction coefficient values and their standard deviation were determined.

\section{Results}

\subsection{Microstructural Characterization}

Table 1 compiles the values of carbon and oxygen content of the two feedstock powders, while the values of carbon and oxygen content of the S-HVOF as-sprayed coatings (P1C and P2C) are given in Table 2 (the P1C sample for analysis of the non-metal content for was sprayed with slightly different parameter set as for the coating used in the tribological investigations [22]).

Figure 1a, b shows the high-resolution FESEM images of the feedstock powders. Figure 1c-f displays the polished cross section of S-HVOF as-sprayed and HIPed S-HVOF coatings. Figure $2 \mathrm{a}-\mathrm{d}$ shows higher-magnification crosssectional SEM images of these coatings. Figure 3 displays the SEM results of the cross sections of the HVOF-JK coating. Figure 4 shows the XRD diffraction pattern of the identified peaks in the S-HVOF as-sprayed and HIPed coatings. Table 3 compiles the results of the Rietveld analysis of the HIPed coatings, based on the diffraction pattern given in Fig. 4.

Figure 5a shows the calculated isothermal section of the $\mathrm{W}-\mathrm{Co}-\mathrm{C}$ system at $1000{ }^{\circ} \mathrm{C}$. The stable $\mathrm{WC}-12 \% \mathrm{Co}$ composition ( 0.41 at. $\% \mathrm{~W}, 0.41$ at.\% $\mathrm{C}$ and 0.18 at.\% Co) is marked in the two-phase field $\mathrm{WC}+\mathrm{Co}$. Beginning at this starting composition, the carbon content is successively reduced until the carbon-free system W-Co (dotted line) is reached. The resulting changes in the phase composition and the amounts of the equilibrium phases are calculated and presented in Fig. $5 \mathrm{~b}$ in $\mathrm{wt} \%$. 
Figures 6 and 7 show TEM analysis of P1C coating at two locations, along with Tables 4 and 5 which show, respectively, the experimental $d$-spacing measured from the different rings in diffraction pattern (DP) 1 and 2 and the reference International Center for Diffraction Data (ICDD) $d$-spacing for some possible phases. In parentheses are the hkl values. The relative intensities of the X-ray reflections are also indicated. Figure 8 shows TEM analysis of P1C-HIP, along with Table 6 which shows the experimental $d$-spacing measured from the different rings in DP and ICDD $d$-spacing for some possible phases. Figure 9 shows TEM analysis of P2C-HIP, along with Table 7 which shows the experimental $d$-spacing measured from the different rings in DP and ICDD $d$-spacing for some possible phases.

\subsection{Sliding Wear and Nanomechanical Tests}

Figure 10 illustrates the SEM observations of the wear track for S-HVOF coatings which slid against the steel ball. Figure 11 shows the SEM observations of test couples which involved ceramic $\left(\mathrm{Si}_{3} \mathrm{~N}_{4}\right)$ ball. Representative SEM observations of the S-HVOF coating and WC-Co ball test couples are revealed in Fig. 12. Average friction coefficient values recorded during the sliding wear tests are shown in Fig. 13. The average friction coefficient for the last $300 \mathrm{~m}$ of sliding distance for all sliding test couples is also shown in Fig. 13. Figure 14 shows the averaged through thickness indentation hardness and modulus values for the HVOF coatings. The average values of wear rate recorded after the sliding wear tests are displayed in Fig. 15. These values (including the standard deviations) are presented as the ball wear rate, coating wear rate and total wear rate, respectively. The average values of the wear rate ratio as well as the mean depth of wear track are also given in this figure.

\section{Discussion}

\subsection{Feedstock Powder Microstructure and Composition}

Powder P1 shows a very heterogeneous structure (Fig. 1a). By EDX analysis, the larger grains appearing bright were found to contain $\mathrm{Co}, \mathrm{W}$ and $\mathrm{C}$, while the very small particles of about $200 \mathrm{~nm}$ in size consisted probably of carbon only. Both the carbon and oxygen contents were surprisingly high, whereupon the carbon content is significantly higher than required for the stoichiometry of $\mathrm{WC}-12 \% \mathrm{Co}$ (5.39 wt\%), supporting the existence of free carbon in the powder (Table 1). The synthesis conditions of this powder are not known; thus, the origin of structure and chemical analysis cannot be interpreted. Powder P2 shows the typical structure of the surface of an agglomerated and sintered particle, showing the fine carbide grains (Fig. 1b).

\subsection{Coating Phase Composition and Microstructure}

The microstructure of as-sprayed S-HVOF and HVOF-JK coatings was discussed in previous publications. Summarized findings from these publications are included here to aid the discussion [22, 23]:

1. The microstructure of the S-HVOF coatings indicated nanosized particles ( $\mathrm{WC}, \mathrm{W}, \mathrm{M}_{6} \mathrm{C}, \mathrm{M}_{12} \mathrm{C}$ ) some of which were inherited from the starting powder, whereas others formed as a result of carbon loss, demonstrating that the S-HVOF process retained the nanocomposite features during coating deposition.

2. TEM investigations indicated nanosized particles in the range of 100-300 $\mathrm{nm}$. These particles were identified as $\mathrm{W}, \mathrm{WC}$ and $\mathrm{Co}_{3} \mathrm{~W}_{3} \mathrm{C}$. In addition, the presence of crystalline Co was detected in the TEM analysis.

3. The dark areas in Fig. 2 for S-HVOF coatings are interlamellar pullouts, where particles (splats or oxides) with low bonding/cohesion were removed during metallographic preparation.

The focus of discussion here is to compare the changes in the coating microstructure after the HIPing post-treatment for the two coatings sprayed from different powders by S-HVOF on the basis of SEM, XRD, TEM investigations, and non-metal content measurements. The XRD pattern shown in Fig. 4 indicates that both as-sprayed S-HVOF coatings (P1C and P2C), according to the broad peak in the 2 -theta range of $35-48^{\circ}$, contain predominantly an amorphous/nanocrystalline phase. However, the crystalline reflexes in these patterns are different. For P1C coating peaks of some retained WC, metallic tungsten and $\mathrm{W}_{2} \mathrm{C}$ with shifted peak positions were observed [22]. For $\mathrm{P} 2 \mathrm{C}$ coating, metallic tungsten was found as the main crystalline phase, together with small peaks of $\mathrm{WC}$ and $\mathrm{W}_{2} \mathrm{C}$ [23]. According to the results of non-metal analyses of the powder (Table 1) and the coatings (Table 2), very strong carbon loss (4.0\% and more) and strong oxygen uptake (1.0\% and more) were found for both coatings. A relatively higher carbon content was retained for $\mathrm{P} 1 \mathrm{C}$ coating, but connected with a higher oxygen content. The oxygen content is typically $<0.2 \mathrm{wt} \%$ in conventional coatings [1]. The differences in carbon and oxygen contents between the coatings $\mathrm{P} 1 \mathrm{C}$ and $\mathrm{P} 2 \mathrm{C}$ are originated in the corresponding different values for the feedstock powders $\mathrm{P} 1$ and $\mathrm{P} 2$, respectively. In addition, the XRD diffraction pattern of suspension sprayed WC-12Co coating from powder 1 (P1C) in this work resembles those of 

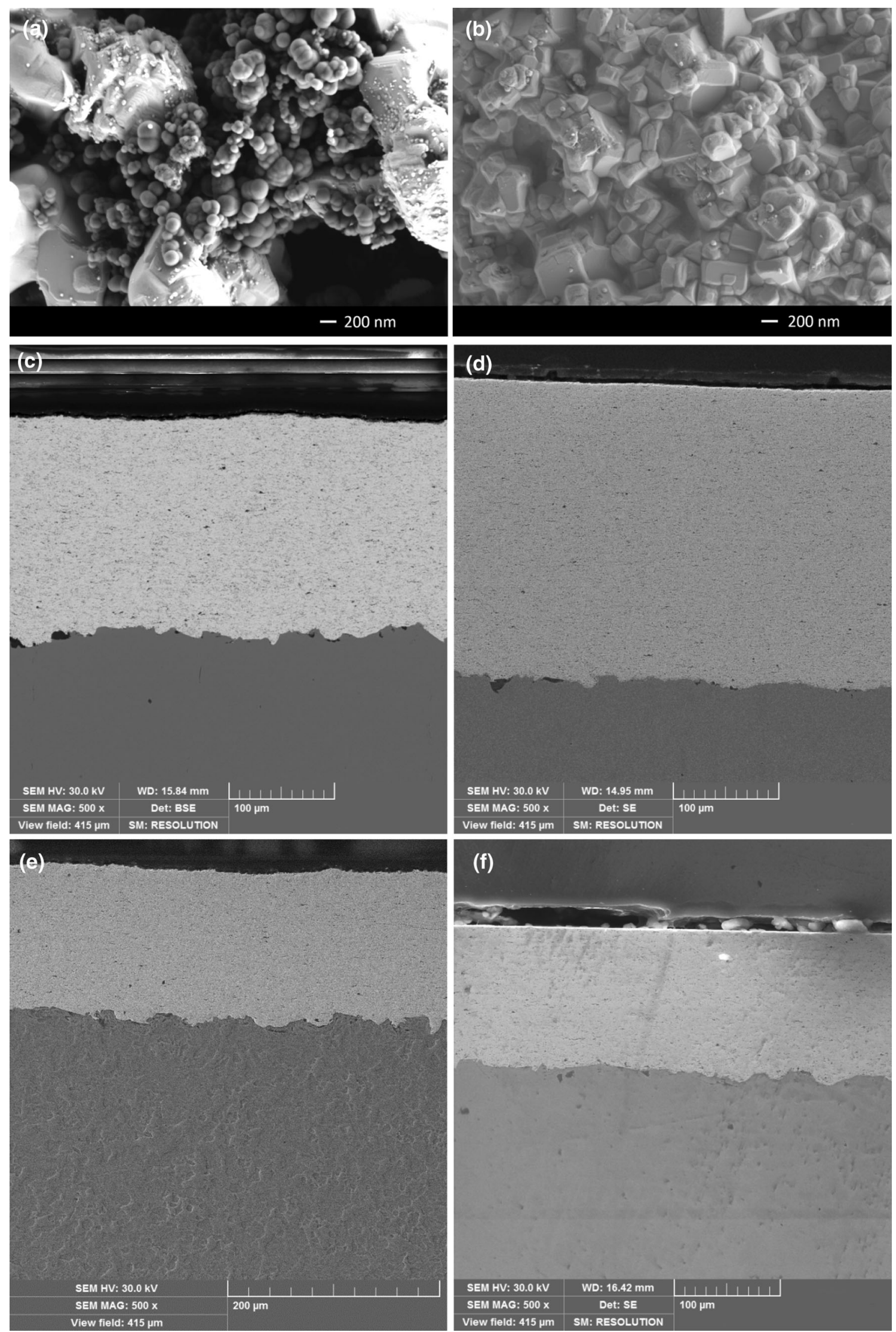
4Fig. 1 High-resolution FESEM images of the feedstock powders morphologies. a Powder P1 by Dong Yang (HK) Int'l Group Limited [22] and b Powder P2 Fujimi Corp., Japan. Cross-sectional SEM micrograph $500 \times$ magnification for coatings deposited from c P1C d P1C-HIP. e P2C. f P2C-HIP

Detonation Gun Spray (DGS) coatings, sprayed with excess of oxygen [18], or from coatings prepared from strongly carbon-deficient powders [41]. Both $\mathrm{W}_{2} \mathrm{C}$ and metallic tungsten are often detected in as-sprayed $\mathrm{WC}-\mathrm{Co}$ coatings [25], including earlier studies of Verdon et al. [42] and Stewart et al. [43]. Both studies [42, 43] investigated the formation of WC-Co coatings with HVOF spray processes which are comparable with the spray process in the current study, using conventional and nanostructured agglomerated and sintered feedstock powders. Stewart et al. [43] have shown that the formation of metallic tungsten depends on the carbide grain size. Thus, the higher carbon loss observed for S-HVOF coatings in our study is in agreement with the results of Stewart et al. [43] taking into account the feedstock properties and spray conditions.
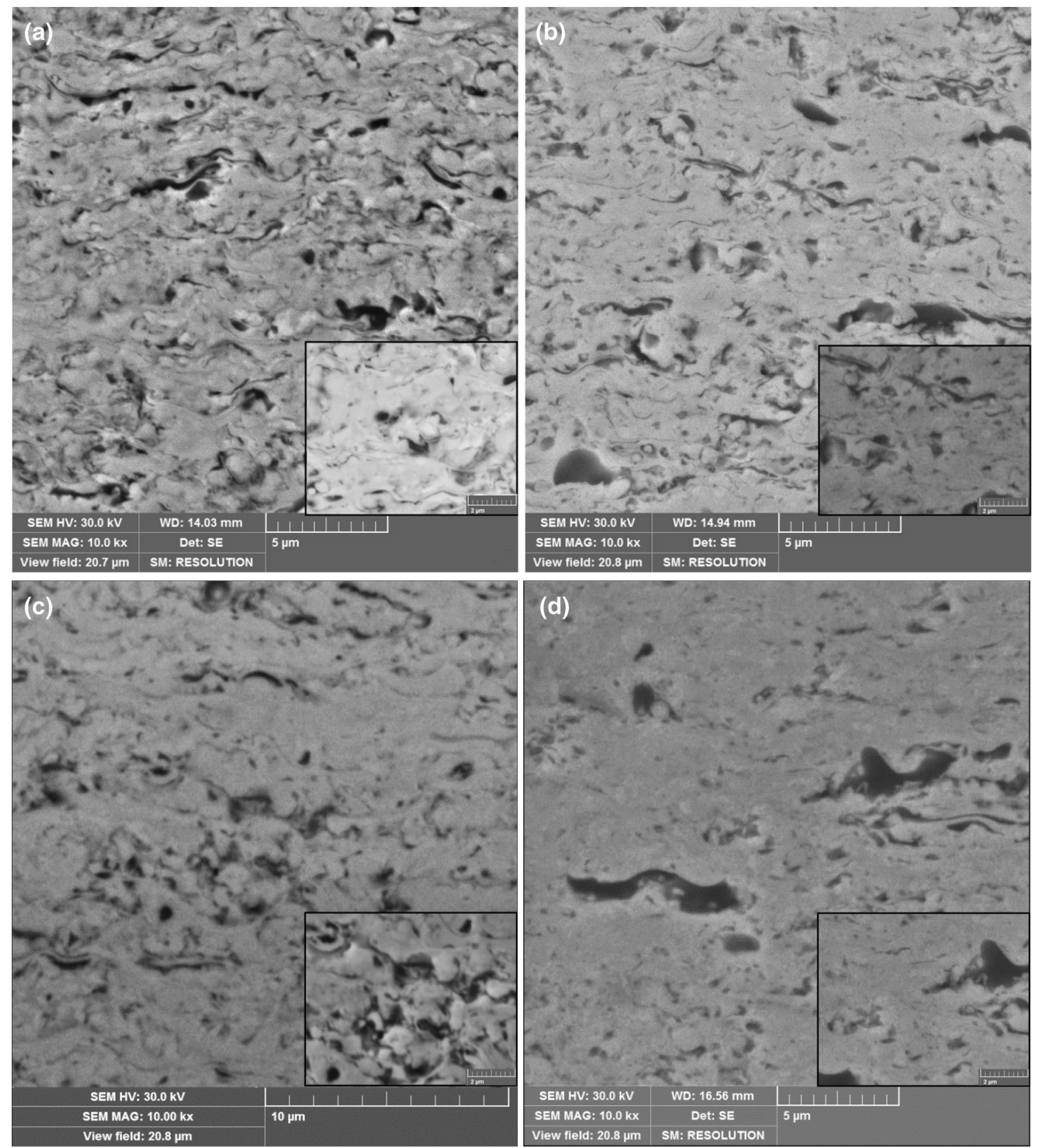

Fig. 2 Cross-sectional SEM micrograph $10 \mathrm{k} \times$ magnification (with $20 \mathrm{k} \times$ magnification inlayed showing $2 \mu \mathrm{m}$ scale bar) for coatings deposited from a P1C b P1C-HIP. c P2C. d P2C-HIP 

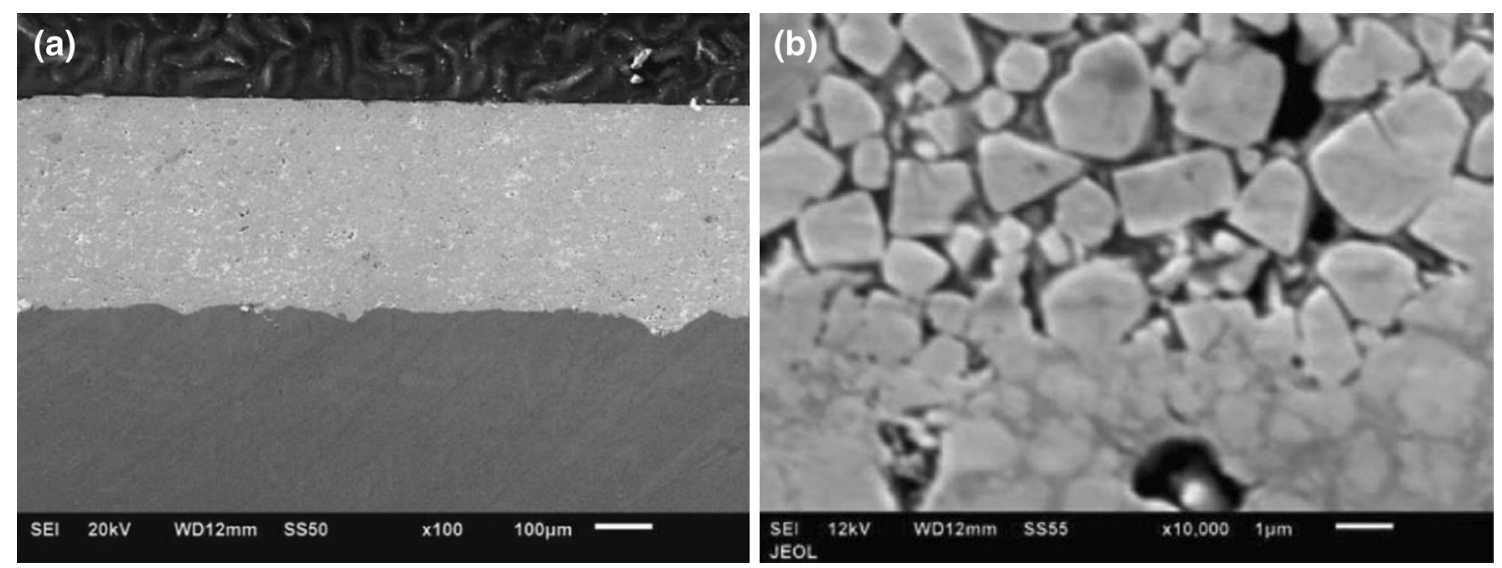

Fig. 3 P3C cross section with increasing magnification $(\mathbf{a}, \mathbf{b})$

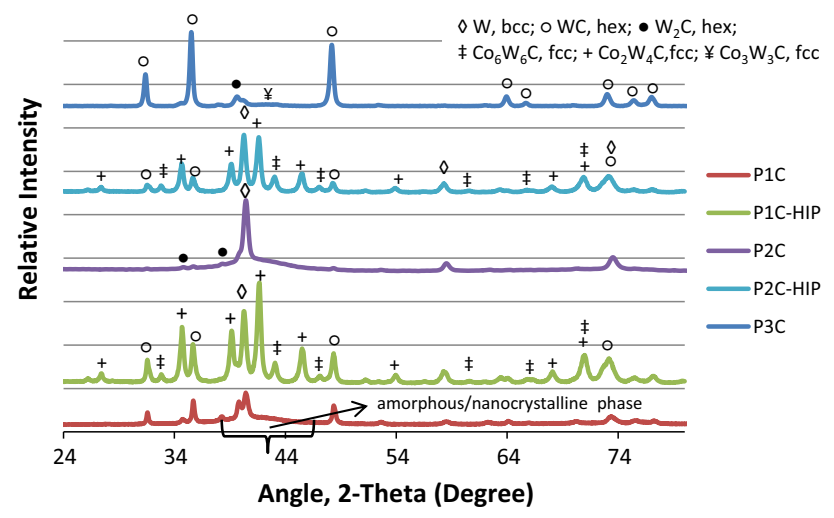

Fig. 4 XRD analysis of coating P1C, P1C-HIP, P2C, P2C-HIP, P3C $[22,23]$

$\mathrm{X}$-ray analysis reveals that for both coatings, after HIPing at $920{ }^{\circ} \mathrm{C}$ (P1C-HIP and P2C-HIP) the amorphous phase and $\mathrm{W}_{2} \mathrm{C}$ disappeared or were considerably minimized, WC and metallic tungsten remain, and new crystalline phases are formed. These are two $\eta$-phases: $\mathrm{M}_{6} \mathrm{C}$ $\left(\mathrm{Co}_{2} \mathrm{~W}_{4} \mathrm{C}\right.$ fits the peaks better than those of $\left.\mathrm{Co}_{3} \mathrm{~W}_{3} \mathrm{C}\right)$ and $\mathrm{M}_{12} \mathrm{C}\left(\mathrm{Co}_{6} \mathrm{~W}_{6} \mathrm{C}\right)$. According to the Rietveld analysis given in Table $3, \mathrm{Co}_{2} \mathrm{~W}_{4} \mathrm{C}$ represents the main phase of both coatings. It should be mentioned also that compared to the as-sprayed state due to the heat treatment, a decrease in both of the carbon and oxygen contents is possible (thus a decrease compared to the values given in Table 2 is possible), due to internal reduction processes.

The thermodynamic calculations performed in this work allow an improved interpretation of the phase composition changes occurring due to HIPing. The isothermal cross section of the $\mathrm{W}-\mathrm{C}-\mathrm{Co}$ phase diagram at $1000{ }^{\circ} \mathrm{C}$ shown in Fig. 5a indicates that two $\eta$-phases $-\mathrm{W}_{6} \mathrm{Co}_{6} \mathrm{C}$ with a defined W/Co ratio and $\mathrm{M}_{6} \mathrm{C}$ with a variable $\mathrm{W} / \mathrm{Co}$ ratio (expressed by the existence of JCPDS standard cards for $\mathrm{Co}_{3} \mathrm{~W}_{3} \mathrm{C}$ and $\mathrm{Co}_{2} \mathrm{~W}_{4} \mathrm{C}$ ) - exist. At the same time, $\mathrm{W}_{2} \mathrm{C}$ does not exist at this temperature, as according to the $\mathrm{W}-\mathrm{C}$ phase diagram [44], it is thermodynamically unstable below $1250{ }^{\circ} \mathrm{C}$. The path of carbon loss from WC-12\% Co to a plain metallic composition crosses several two- and three-phase fields; the corresponding phase compositions are displayed in Fig. 5b. The $\mathrm{W}_{6} \mathrm{Co}_{6} \mathrm{C}$ phase appears twice as an equilibrium phase, both for relatively low and high carbon loss. But most important, metallic tungsten appears as an equilibrium phase with higher carbon loss.

For the comparison of the results of the Rietveld analysis (Table 3) with those of the thermodynamic calculation (Fig. 5b), it should be taken into account that the carbon content of the as-sprayed coating might be further decreased due to the HIPing, the thermodynamic equilibrium was not reached at the HIPing conditions $\left(920^{\circ} \mathrm{C} / 2 \mathrm{~h}\right)$, and that the calculation was performed for $1000{ }^{\circ} \mathrm{C}$. Nonetheless, a good qualitative agreement is found between the experimental and
Table 3 Phase content of the HIPed coatings (wt \%) according to Rietveld analysis phase

\begin{tabular}{lcc}
\hline Phase & Coating obtained from Powder 1 (P1) & Coating obtained from Powder 2 (P2) \\
\hline $\mathrm{WC}$ & 11.3 & 5.4 \\
$\mathrm{~W}_{2} \mathrm{C}$ & 2.9 & 2.0 \\
$\mathrm{~W}$ & 15.3 & 20.3 \\
$\mathrm{Co}_{6} \mathrm{~W}_{6} \mathrm{C}$ & 11.2 & 16.5 \\
$\mathrm{Co}_{2} \mathrm{~W}_{4} \mathrm{C}$ & 59.3 & 55.8 \\
\hline
\end{tabular}


Fig. 5 a Calculated isothermal section of the $\mathrm{WC}-\mathrm{Co}-\mathrm{C}$ phase diagram at $1000{ }^{\circ} \mathrm{C}$. Path of decreasing carbon content starting from composition WC$12 \%$ Co. b Phase composition and amounts of equilibrium phases along the path of carbon loss shown in (a)
(a)

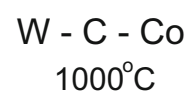

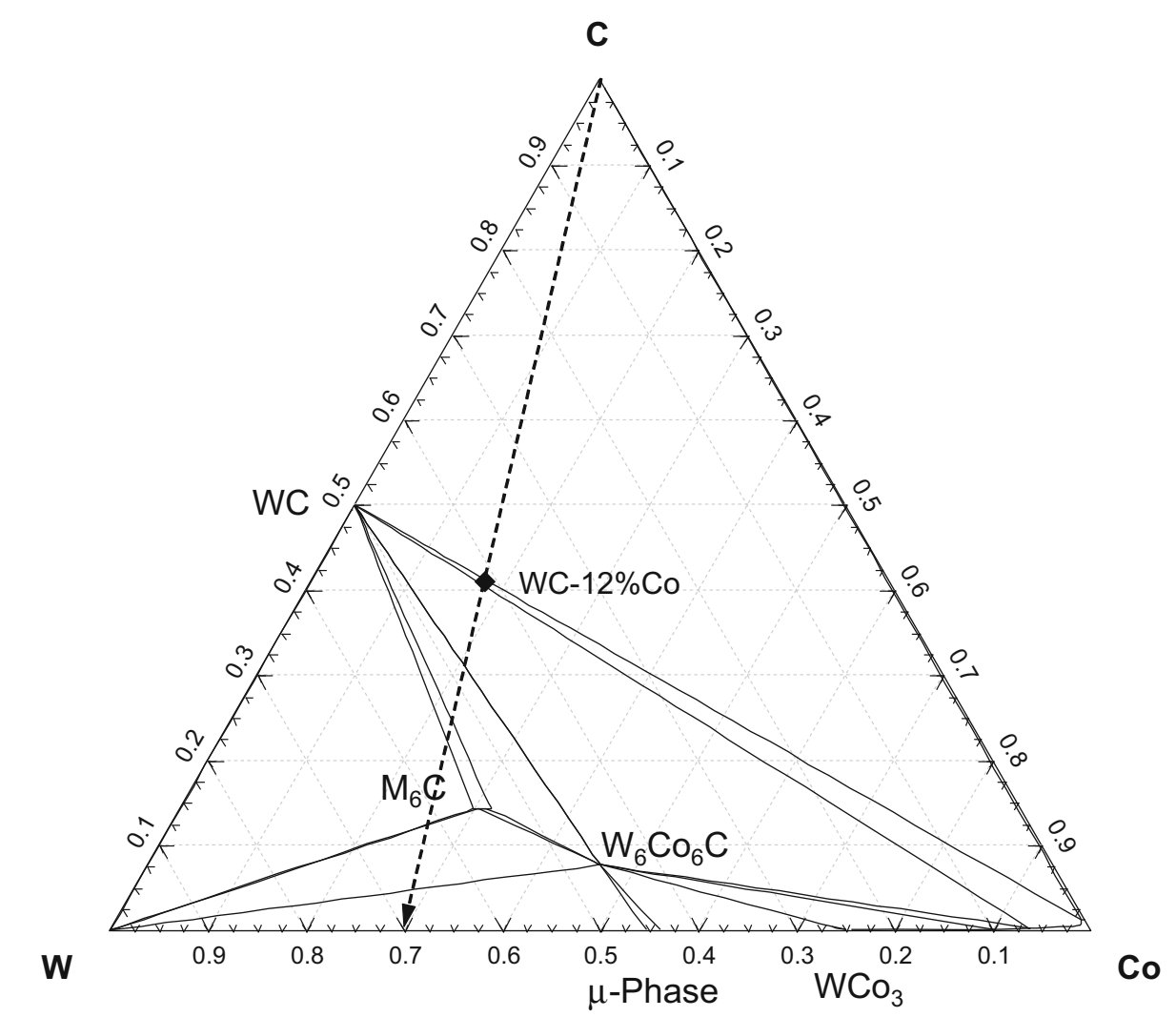

(b)

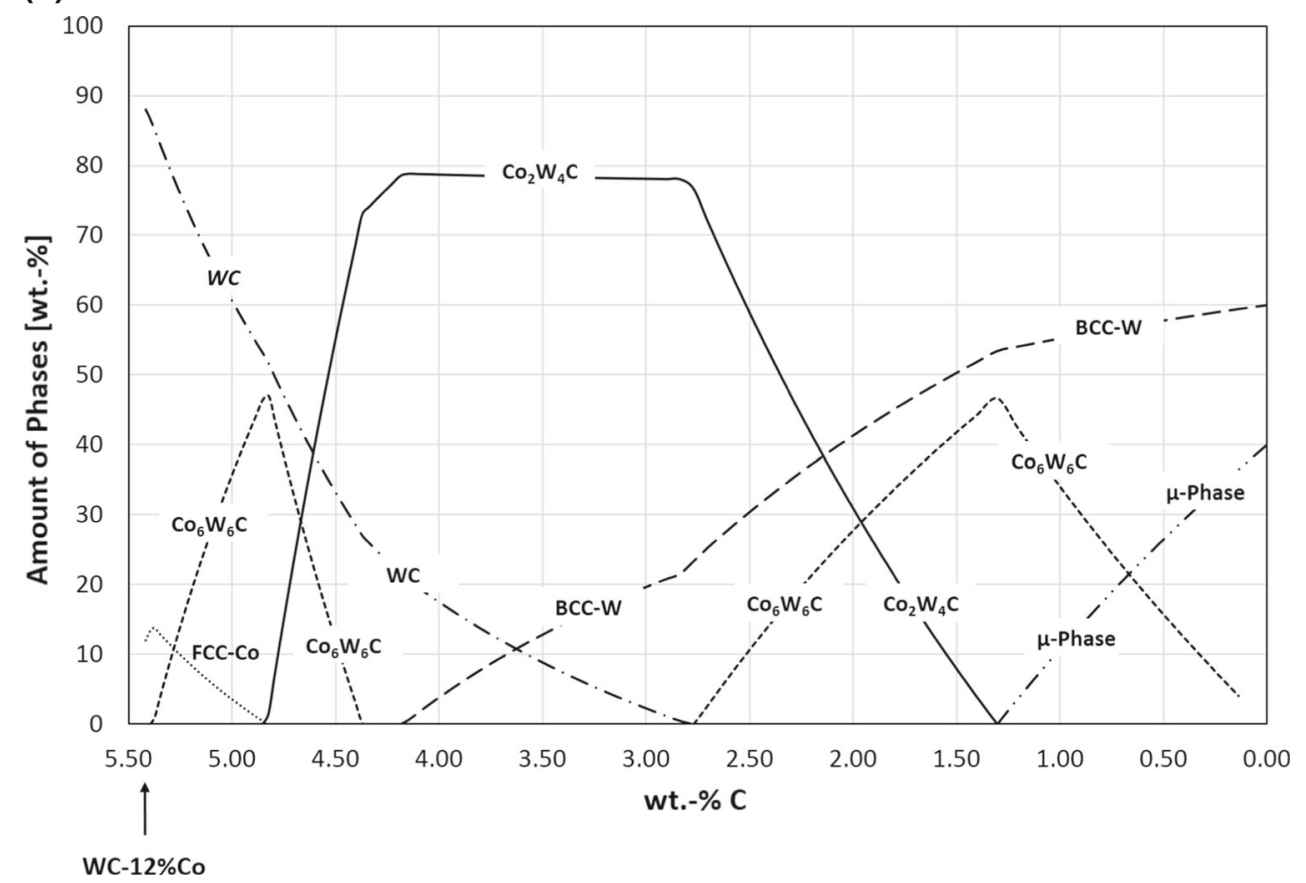

theoretical results. As the carbon content for the $\mathrm{P} 2 \mathrm{C}-\mathrm{HIP}$ condition is presumably lower than for the P1C-HIP condition, the $\mathrm{Co}_{6} \mathrm{~W}_{6} \mathrm{C}$ and $\mathrm{W}$ contents are higher, while the
$\mathrm{Co}_{2} \mathrm{~W}_{4} \mathrm{C}$ content is lower. Remaining $\mathrm{WC}$ and $\mathrm{W}_{2} \mathrm{C}$ exist probably in both samples by kinetic reasons and the fact that the thermodynamic equilibrium was not reached. 
Fig. 6 Plane-view TEM image of a polycrystalline region in the upper part sample surface (P1C)
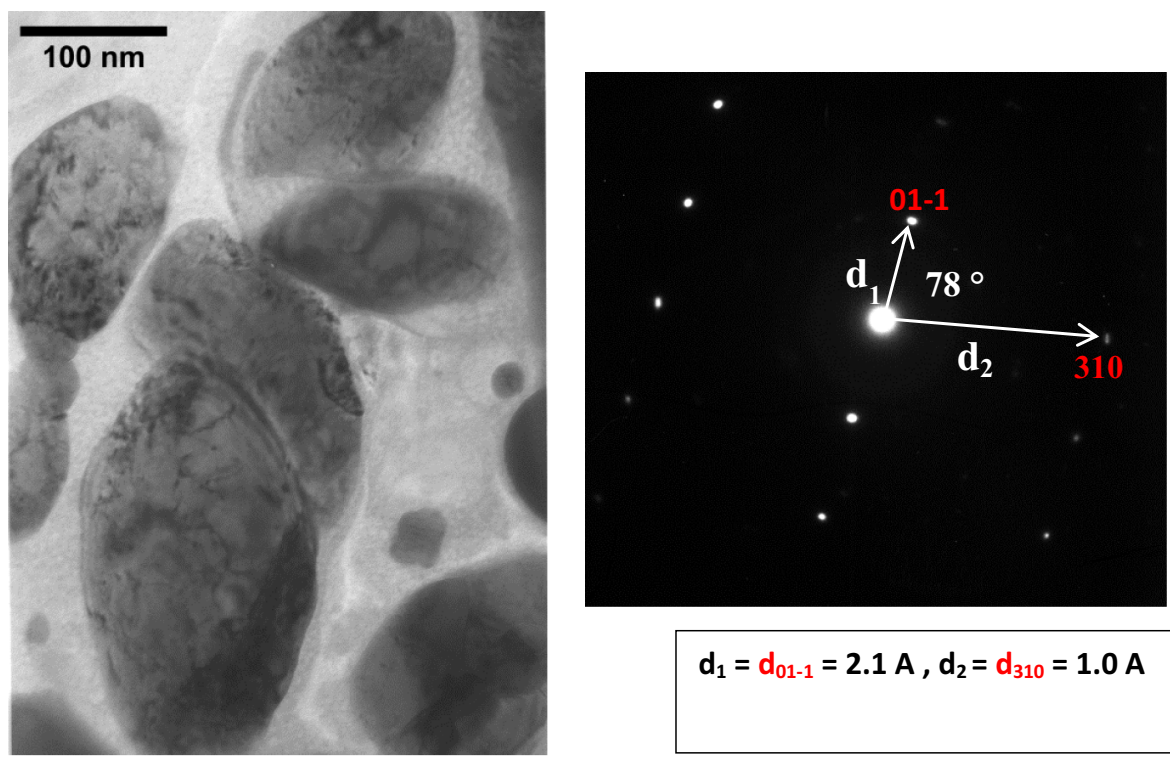

$d_{1}=d_{01-1}=2.1 A, d_{2}=d_{310}=1.0 A$

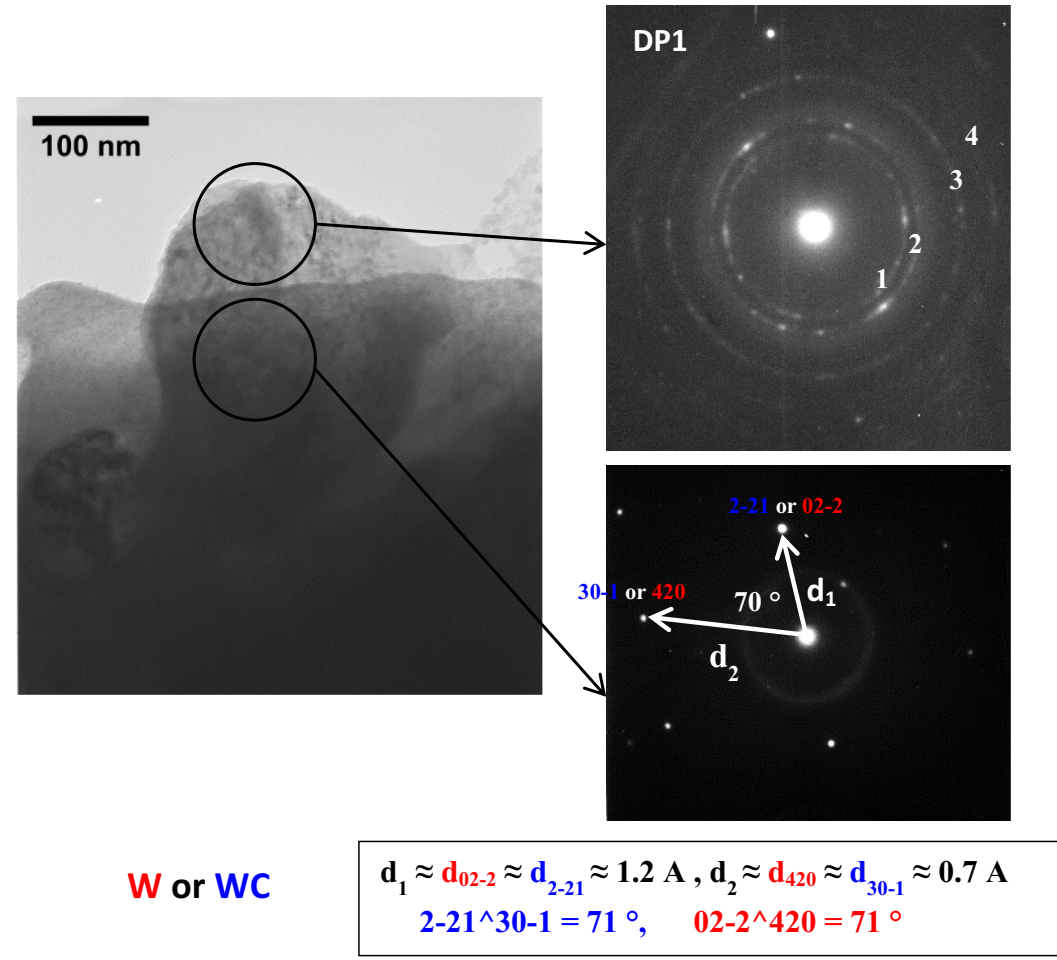

The SEM micrographs of the cross sections of the assprayed and HIPed coatings as revealed in Figs. 1 and 2 indicated lamella microstructure with low porosity. The nanostructured features observed in these figures originated from the different WC-12Co powders [22, 23].

The TEM analysis of these nanocomposite particles for as-sprayed P1C coating (Figs. 6, 7) indicated the presence of WC. Similarly, $\mathrm{W}_{2} \mathrm{C}, \mathrm{W}, \mathrm{Co}_{3} \mathrm{~W}_{3} \mathrm{C}, \mathrm{Co}_{6} \mathrm{~W}_{6} \mathrm{C}$ and $\mathrm{Co}_{3-}$ $\mathrm{W}_{9} \mathrm{C}_{4}$ were also observed as possible phases. The diffraction pattern (DP) for this coating indicated that the peaks of $\mathrm{WC}, \mathrm{W}_{2} \mathrm{C}, \mathrm{W}, \mathrm{Co}_{6} \mathrm{~W}_{6} \mathrm{C}$ and $\mathrm{Co}_{2} \mathrm{~W}_{4} \mathrm{C}$ are the likely microstructural phases. The possibility of existence of $\eta$ phases $\mathrm{Co}_{6} \mathrm{~W}_{6} \mathrm{C}$ and $\mathrm{Co}_{2} \mathrm{~W}_{4} \mathrm{C}$, and the $\kappa$-phase $\mathrm{Co}_{3} \mathrm{~W}_{9} \mathrm{C}_{4}$ in the $\mathrm{P} 1 \mathrm{C}$ coating was indicated only by the TEM analysis. This may be attributed to the sensitivity of TEM in identifying small crystalline phases. Regardless of that, the uncertainty in identifying the different phases is due to the coincidence of their $d$-spacing values. It is also possible that, independently of the thermodynamic stability, small unstable crystalline phases could be trapped inside the main phases. Additionally, crystallites with small stoichiometric deviations could also appear (hence the 


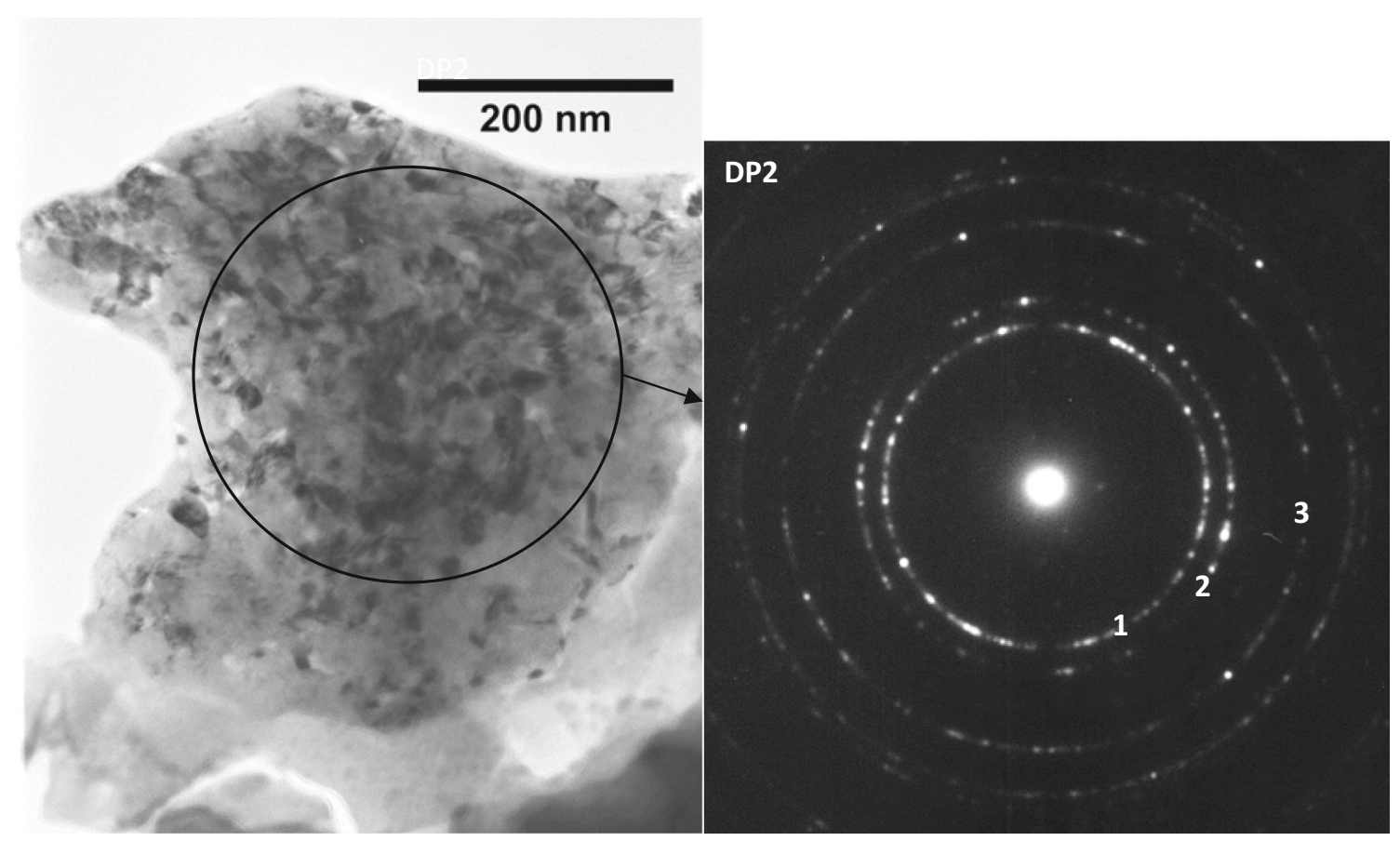

Fig. 7 Plane-view TEM image of another polycrystalline region in the upper part sample surface (P1C)

Table 4 Experimental d-spacing (P1C) measured from the different rings in DP1 and closest d-spacing available in ICDD for some possible phases

\begin{tabular}{|c|c|c|c|c|c|c|}
\hline \multirow[b]{2}{*}{ Ring number } & \multirow[b]{2}{*}{$\operatorname{dexp}(\AA)$} & \multicolumn{5}{|c|}{$\mathrm{d}(\AA)(\mathrm{ICDD})$} \\
\hline & & $\begin{array}{l}\text { W } \\
\text { (Hex.) }\end{array}$ & $\begin{array}{l}\text { WC } \\
\text { (Hex.) }\end{array}$ & $\begin{array}{l}\mathrm{W}_{2} \mathrm{C} \\
\text { (Hex.) }\end{array}$ & $\begin{array}{l}\mathrm{Co}_{3} \mathrm{~W}_{3} \mathrm{C} \text { or } \mathrm{Co}_{6} \mathrm{~W}_{6} \mathrm{C} \\
\text { (Cubic) }\end{array}$ & $\begin{array}{l}\mathrm{Co}_{3} \mathrm{~W}_{9} \mathrm{C}_{4} \\
\text { (Hex.) }\end{array}$ \\
\hline \multirow[t]{2}{*}{1} & 2.7 & - & $2.8(001)$ & $2.6(110)$ & $2.8(400)$ & $2.6(210)$ \\
\hline & & & Int 44 & Int22 & Int 25 & Int 25 \\
\hline \multirow[t]{2}{*}{2} & 2.3 & $2.2(011)$ & - & $2.3(-1-11)$ & $2.3(422)$ & $2.2(301)$ \\
\hline & & Int 100 & & Int100 & Int65 & Int100 \\
\hline \multirow[t]{2}{*}{3} & 1.7 & $1.6(002)$ & - & $1.7(-1-12)$ & $1.7(533)$ & $1.7(402)$ \\
\hline & & Int17 & & Int15 & Int 1 & Int 11 \\
\hline \multirow[t]{2}{*}{4} & 1.4 & $1.3(112)$ & $1.4(110)$ & $1.5(300)$ & $1.4(731)$ & $1.4(205)$ \\
\hline & & Int36 & Int 15 & Int16 & Int12 & Int5 \\
\hline
\end{tabular}

In parentheses are the hkl values. The relative intensities of the X-ray reflections are also indicated

\begin{tabular}{|c|c|c|c|c|c|c|}
\hline \multirow[b]{2}{*}{ Ring number } & \multirow[b]{2}{*}{$\operatorname{dexp}(\AA)$} & \multicolumn{5}{|c|}{$\mathrm{d}(\AA)(\mathrm{ICDD})$} \\
\hline & & $\begin{array}{l}\text { W } \\
\text { (Hex.) }\end{array}$ & $\begin{array}{l}\text { WC } \\
\text { (Hex.) }\end{array}$ & $\begin{array}{l}\mathrm{W}_{2} \mathrm{C} \\
\text { (Hex.) }\end{array}$ & $\begin{array}{l}\mathrm{Co}_{3} \mathrm{~W}_{3} \mathrm{C} \text { or } \mathrm{Co}_{6} \mathrm{~W}_{6} \mathrm{C} \\
\text { (Cubic) }\end{array}$ & $\begin{array}{l}\mathrm{Co}_{3} \mathrm{~W}_{9} \mathrm{C}_{4} \\
\text { (Hex.) }\end{array}$ \\
\hline \multirow[t]{2}{*}{1} & 2.0 & - & $1.9(101)$ & - & $2.1(511)$ & $2.1(203)$ \\
\hline & & & Int83 & & Int100 & Int64 \\
\hline \multirow[t]{2}{*}{2} & 1.7 & $1.6(002)$ & - & $1.7(-1-12)$ & $1.6(551)$ & 1.7 (402) \\
\hline & & Int17 & & Int15 & Int13 & Int11 \\
\hline \multirow[t]{2}{*}{3} & 1.2 & $1.3(112)$ & $1.9(102)$ & $1.3(-2-21)$ & $1.2(911)$ & $1.2(206)$ \\
\hline & & Int36 & Int13 & Int12 & Int4 & Int2 \\
\hline
\end{tabular}

In parentheses are the hkl values. The relative intensities of the X-ray reflections are also indicated
Table 5 Experimental d-spacing (P1C) measured from the different rings in DP2 and closest d-spacing available in ICDD for some possible phases 
Fig. 8 Plane-view TEM image and DP obtained with a bigger aperture from the sample surface: observation of an amorphous feature and polycrystalline rings (P1C-HIP)
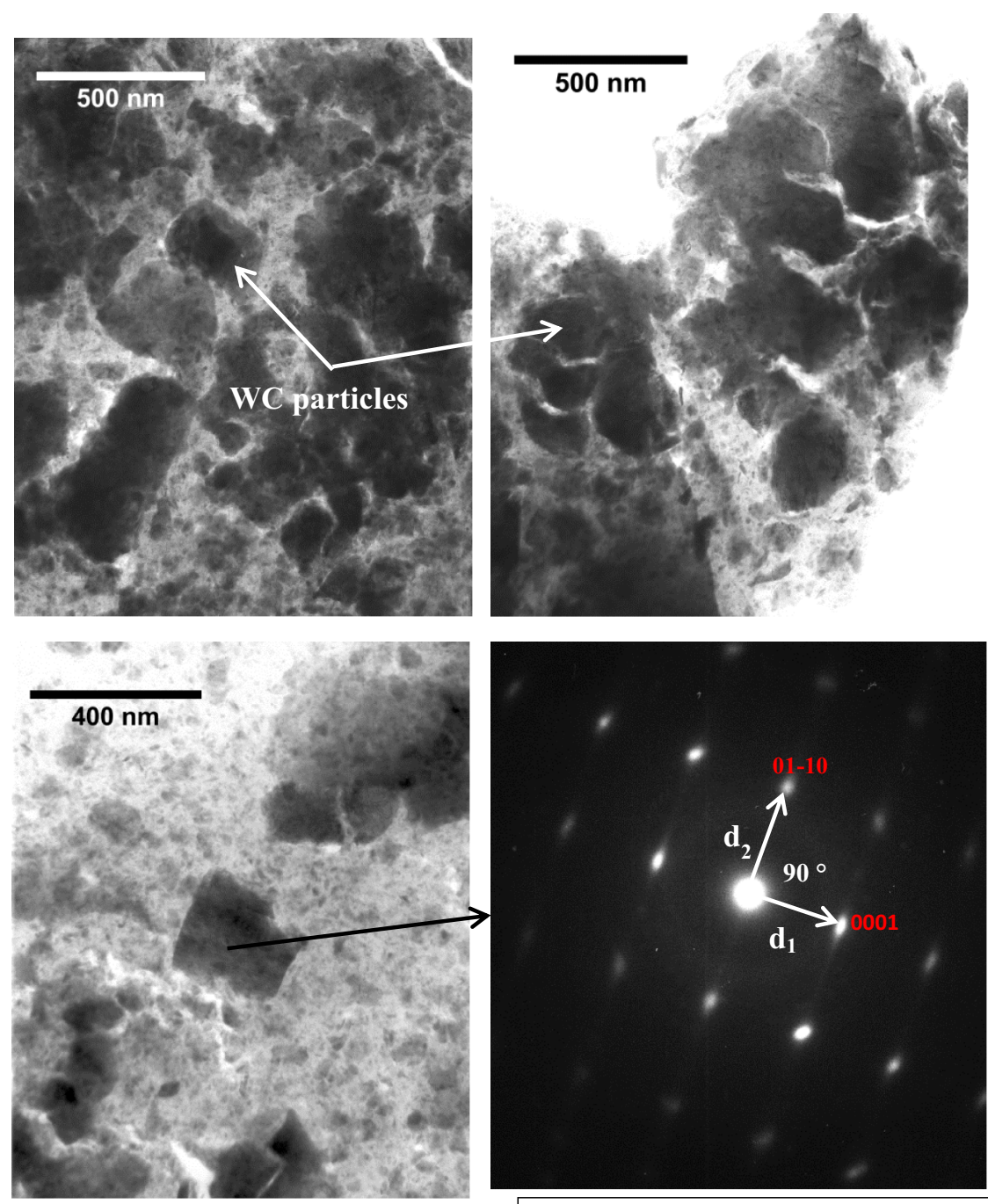

$$
\text { WC } \begin{gathered}
\mathrm{d}_{1}=\mathrm{d}_{0001}=2.5 \mathrm{~A}, \mathrm{~d}_{2}=\mathrm{d}_{01-10}=2.8 \mathrm{~A} \\
0001^{\wedge} 01-10 \text { angle }=90^{\circ}
\end{gathered}
$$

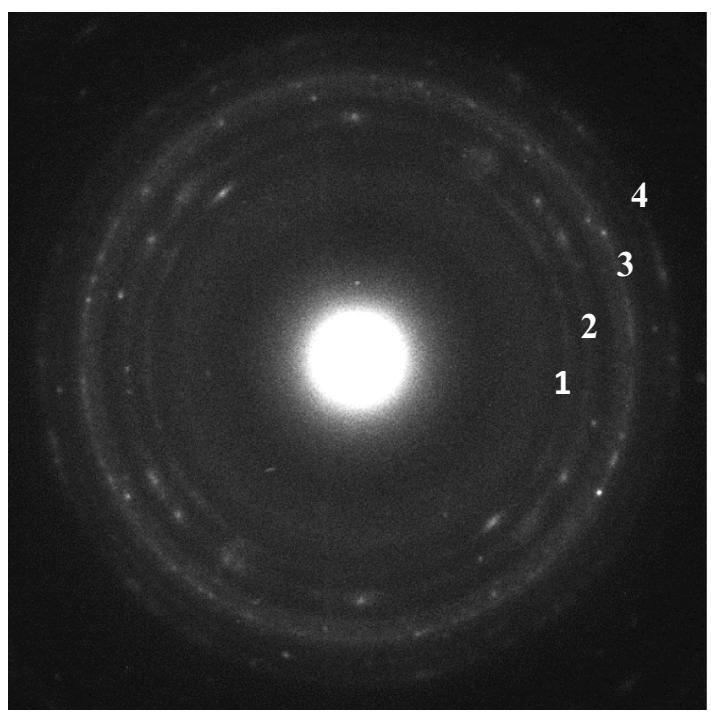


Table 6 Experimental d-spacing (P1C-HIP) measured from the different rings and closest d-spacing available in ICDD for some possible phases

\begin{tabular}{|c|c|c|c|c|c|c|}
\hline \multirow[b]{2}{*}{ Ring number } & \multirow[b]{2}{*}{$\operatorname{dexp}(\AA)$} & \multicolumn{5}{|c|}{$\mathrm{d}(\AA)(\mathrm{ICDD})$} \\
\hline & & $\begin{array}{l}\text { W } \\
\text { (Hex.) }\end{array}$ & $\begin{array}{l}\text { WC } \\
\text { (Hex.) }\end{array}$ & $\begin{array}{l}\mathrm{W}_{2} \mathrm{C} \\
\text { (Hex.) }\end{array}$ & $\begin{array}{l}\mathrm{Co}_{3} \mathrm{~W}_{3} \mathrm{C} \text { or } \mathrm{Co}_{6} \mathrm{~W}_{6} \mathrm{C} \\
\text { (Cubic) }\end{array}$ & $\begin{array}{l}\mathrm{Co}_{3} \mathrm{~W}_{9} \mathrm{C}_{4} \\
\text { (Hex.) }\end{array}$ \\
\hline \multirow[t]{2}{*}{1} & 2.7 & - & $2.8(001)$ & $2.6(110)$ & $2.8(400)$ & $2.8(112)$ \\
\hline & & & Int44 & Int22 & Int25 & Int 4 \\
\hline \multirow[t]{2}{*}{2} & 2.4 & - & $2.5(100)$ & $2.3(-1-11)$ & $2.5(311)$ & $2.6(210)$ \\
\hline & & & Int100 & Int100 & Int40 & Int49 \\
\hline \multirow[t]{2}{*}{3} & 2.1 & $2.2(011)$ & - & - & $2.1(511)$ & $2.2(301)$ \\
\hline & & Int 100 & & & Int100 & Int100 \\
\hline \multirow[t]{2}{*}{4} & 1.8 & - & $1.9(101)$ & $1.7(-1-12)$ & $1.8(442)$ & $1.8(311)$ \\
\hline & & & Int83 & Int15 & Int3 & Int2 \\
\hline
\end{tabular}

In parentheses are the hkl values. The relative intensities of the X-ray reflections are also indicated
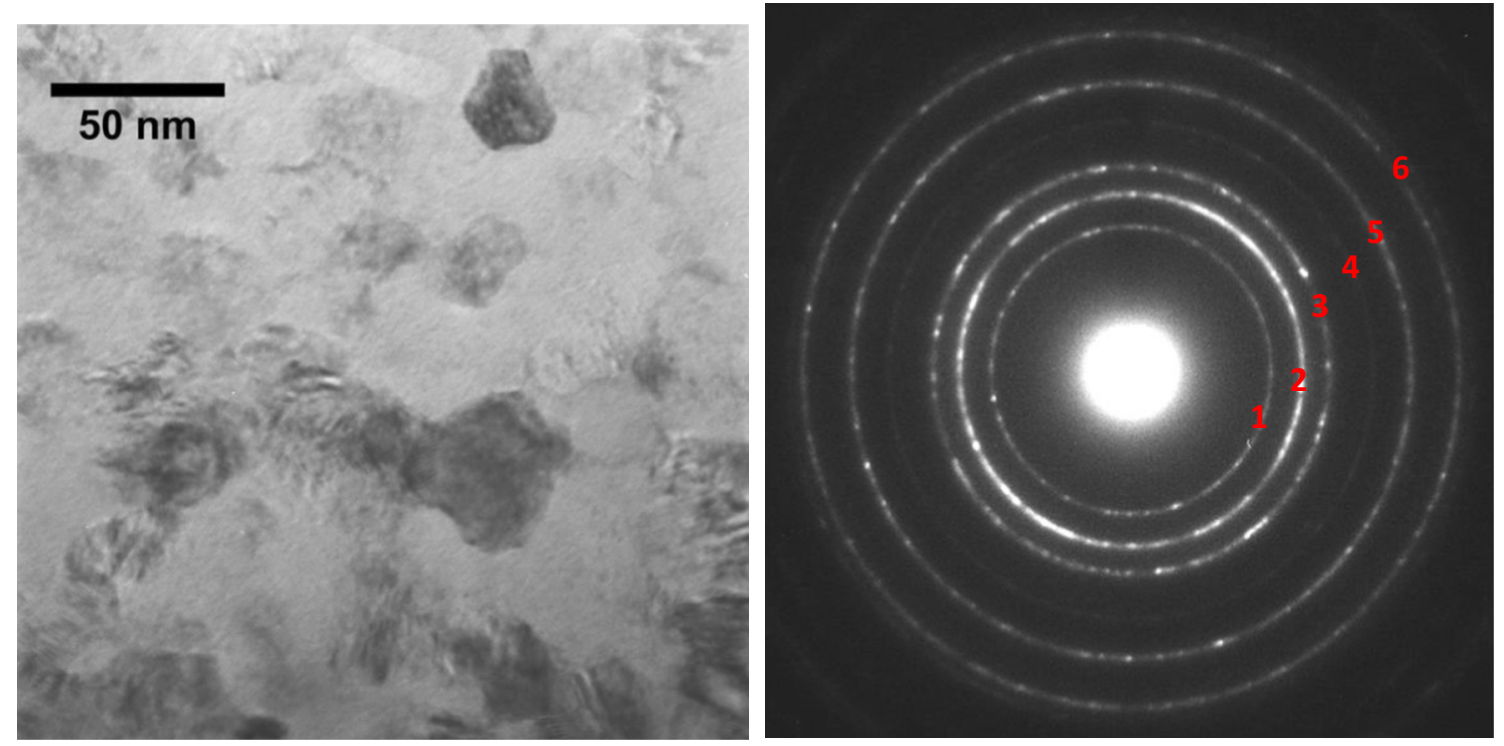

Fig. 9 Plane-view TEM image and a polycrystalline diffraction pattern from the sample surface (P2C-HIP) [23]

broadening of the line of the rings of the diffraction pattern). Figures 6 and 7 indicate that the typical grain size of crystals was less than $50 \mathrm{~nm}$. For discussion purpose, these particles in the deposited coating were collectively termed as "nanosized particles" [22, 23]. The TEM investigation indicated that these nanosized particles were well distributed within the microstructure. Similar trend was observed in the P2C as-sprayed S-HVOF coating with the exception of metallic Co which was identified by the TEM analysis [23] but not observed for P1C coating or the XRD analysis (Fig. 4).

The TEM analysis of the P1C-HIP coating (Fig. 8) indicates WC grains of approximately $100 \mathrm{~nm}$ in size which were homogeneously distributed on the sample surface. These grains are relatively larger than those observed in the as-sprayed conditions, indicating crystallization of amorphous/nanocrystalline phases and possible grain growth. The polycrystalline diffraction pattern from the sample surface is shown in Fig. 8. The $d$-spacing and intensities related to the different rings are given in Table 6. With a bigger aperture, the DP from the HIPed S-HVOF coating shows an amorphous feature as observed in the DP pattern of Fig. 8. However, polycrystalline diffraction rings are also observed. The presence of WC on the sample surface, already observed from the singlecrystal particle DP, is confirmed with the polycrystalline DP. The occurrence of ring 3 in the DP (see Table 6) indicates the possible presence of $\mathrm{W}$, the $\eta$-phases $\mathrm{M}_{6} \mathrm{C}$ and $\mathrm{M}_{12} \mathrm{C}$ and the $\kappa$-phase $\mathrm{Co}_{3} \mathrm{~W}_{9} \mathrm{C}_{4}$.

The TEM analysis of the P2C-HIP coating (Fig. 9) indicates grains with a size of approximately $20 \mathrm{~nm}$ which were homogeneously distributed on the sample surface. The TEM analysis of the as-sprayed coating [23] did indicate larger (50 to $400 \mathrm{~nm}$ )-sized grains, so the smaller grain size in Fig. 9 may be attributed to a particular location in the sample. The $d$-spacing and intensities related to 
Table 7 Experimental d-spacing (P2C-HIP) and intensity measured from the different rings and closest d-spacing available in ICDD for some possible phases

\begin{tabular}{lllllll}
\hline \multirow{2}{*}{ Ring number } & $\operatorname{dexp}(\AA)$ & $\begin{array}{l}\mathrm{d}(\AA)(\mathrm{ICDD}) \\
(\mathrm{Hex} .)\end{array}$ & $\begin{array}{l}\mathrm{WC} \\
(\mathrm{Hex} .)\end{array}$ & $\begin{array}{l}\mathrm{W}_{2} \mathrm{C} \\
(\mathrm{Hex} .)\end{array}$ & $\begin{array}{l}\mathrm{Co}_{3} \mathrm{~W}_{3} \mathrm{C} \text { or } \mathrm{Co}_{6} \mathrm{~W}_{6} \mathrm{C} \\
(\mathrm{Cubic})\end{array}$ & $\begin{array}{l}\mathrm{Co}_{3} \mathrm{~W}_{9} \mathrm{C}_{4} \\
(\mathrm{Hex} .)\end{array}$ \\
\hline 1 & 3 & - & - & - & - & $3.1(201)$ \\
& & & & & & Int7 \\
2 & 2.4 & - & $2.5(100)$ & $2.3(-1-11)$ & $2.5(331)$ & $2.6(210)$ \\
& Int42 & & Int100 & Int100 & Int40 & Int49 \\
3 & 2.1 & $2.2(011)$ & - & - & $2.1(511)$ & $2.2(301)$ \\
& Int46 & Int100 & & & Int100 & Int100 \\
4 & 1.7 & - & - & $1.7(-1-12)$ & $1.7(533)$ & $1.7(401)$ \\
& Int16 & & & Int15 & Int1 \\
5 & 1.5 & $1.6(002)$ & $1.4(002)$ & $1.5(300)$ & $1.5(642)$ & $1.6(214)$ \\
& Int35 & Int17 & Int5 & Int16 & Int2 & Int20 \\
6 & 1.3 & $1.3(112)$ & $1.3(111)$ & $1.3(-1-13)$ & $1.3(822)$ & $1.6(305)$ \\
& Int24 & Int36 & Int15 & Int15 & Int45 & Int55 \\
\hline
\end{tabular}

In parentheses are the hkl values. The relative intensities of the X-ray reflections are also indicated the different rings are given in Table 7 . The high intensity of ring 2 is compatible with the presence of WC and/or $\mathrm{W}_{2} \mathrm{C}$ on the sample surface. The observation of ring 1 indicates the presence of the $\kappa$-phase $\mathrm{Co}_{3} \mathrm{~W}_{9} \mathrm{C}_{4}$; however, once again this phase was not identified in the XRD pattern and should be present in a very small amount. The HIPing process therefore resulted in the crystallization of the amorphous phases along with the formation of eta-phases $\left(\mathrm{M}_{6} \mathrm{C}, \mathrm{M}_{12} \mathrm{C}\right)$. The phases identified in the TEM analysis of HIPed coatings are consistent with the XRD phases shown in Fig. 4. The relative intensity of $\mathrm{Co}_{2} \mathrm{~W}_{4} \mathrm{C}$ is the highest after the HIPing for P1C-HIP coating, whereas the P2CHIP coating indicates that the relative intensity of $\mathrm{W}$ was the highest. These differences can be mainly attributed to the different carbon contents.

\subsection{Nanomechanical Response}

The S-HVOF coatings presented similar an even slightly higher microhardness values when compared to conventional HVOF coating (P3C). The HIPing treatment allowed an improvement in the S-HVOF coating hardness up to 1200 HV0.3 (Table 2).

Through thickness nanohardness values of coatings presented in Fig. 14a indicate a dependency of averaged hardness values on both the as-sprayed coatings and HIPing post-treatment. The averaged values of nanohardness are lower for as-sprayed P1C coating in comparison with as-sprayed $\mathrm{P} 2 \mathrm{C}$ coating. This is consistent with the averaged microhardness values shown in Table 2, albeit the higher standard deviation of P2C. The averaged nanohardness values for as-sprayed $\mathrm{P} 2 \mathrm{C}$ coating are similar to that of conventional HVOF-JK (as-sprayed P3C) coatings. The HIPing post-treatment resulted in the relative increase in the averaged nanohardness values. This increase in hardness is attributed to the crystallization of amorphous phases in the coating microstructure along with the complexity of the microstructure of P1 starting powder (Fig. 1a; Table 1). Another reason for the relative increase in hardness is the densification of the coating (i.e., solidstate diffusion at high temperature). Although porosity was not quantified in the current study due to pullout of loose particles, the mechanism of densification or collapse of porosity during HIPing can be seen in the published literature [39]. Previous studies on WC-based hardmetal coatings have indicated a similar trend of hardness after the HIPing post-treatment $[15,16]$. A similar trend of increase in hardness can also be observed for the microhardness values shown in Table 2. There is an increase in substrate hardness near the coating substrate interface for P2C coating. This is attributed to a possible higher substrate heating during S-HVOF deposition in comparison with conventional HVOF-JK P3C coatings.

Elastic modulus values also showed a trend of increase in values similar to the nanohardness (Fig. 14b) after the HIPing post-treatment. The increase in elasticity after the HIPing post-treatment is attributed to improved intersplat metallurgical bonding. This trend is also consistent with previous investigation on the HIPing post-treatment of hardmetal coatings $[15,16]$. The averaged through thickness modulus values are higher for as-sprayed P2C coating, when compared to as-sprayed P1C coating and also conventional HVOF-JK (as-sprayed P3C) coatings. The difference in elasticity between the HIPed coatings (P1C-HIP 
and $\mathrm{P} 2 \mathrm{C}-\mathrm{HIP}$ ) is not as marked as in the as-sprayed conditions ( $\mathrm{P} 1 \mathrm{C}$ and $\mathrm{P} 2 \mathrm{C}$ ). This difference is attributed to the non-equilibrium microstructure of as-sprayed coatings.

\subsection{Sliding Wear Performance}

The mechanical properties of the coating and ball materials are summarized in Tables 8 and 9. The wear rate performance and the wear mechanism were dependent on the test couples. For the tests involving steel and ceramic ball couples, the total wear rate (Fig. 15c) indicated that the performance of the as-sprayed P1C coating was better than that of as-sprayed P2C coating. For both as-sprayed coatings, an increase in sliding wear performance after the HIPing post-treatment was observed which is consistent with the increased hardness and modulus values after the HIPing post-treatment (Sect. 4.3). This difference in total wear rate performance showed marginal differences in assprayed coatings (P1C, P2C), albeit higher standard deviation of as-sprayed coatings and a decrease in wear performance for P2C-HIP coating for the WC-Co ball test couples. This is attributed to the fact that the total wear rate was dominated by the ball wear rate (Fig. 15a), which was lowest for the WC-Co ball due to its high hardness and elastic modulus. These values are comparable to the WC$12 \%$ Co coatings sprayed by JP-5000 [22] previously investigated by the authors and shown in Fig. 15, albeit slightly higher than expected coating wear rate (Fig. 15b) against steel ball, which was reported due to the delamination wear of the coating. A trend different to the total wear rate is, however, observed when comparing the coating wear rates (Fig. 15b), which is highest against the ceramic ball followed by steel and WC-Co ball couples. HIPing post-treatment shows an increase in coating wear resistance against the ceramic and WC-Co balls but not for the steel ball. Another observation in Fig. 15b is the lowest wear rate of HVOF-JK (as-sprayed P3C) coatings for all ball couples. The dependency between the ball and coating wear is also illustrated in Fig. 15d, which shows the ratio of ball to coating wear rate. Here, the couples of WC-Co balls against as-sprayed $\mathrm{P} 1 \mathrm{C}$ and $\mathrm{P} 2 \mathrm{C}$ coatings show a marked difference. These dependencies of the ball and coating wear rates, along with the role of wear debris, influencing the total wear rate can be considered via the changes in the failure mechanisms for the test couples.

\subsubsection{Comparison of Wear Mechanisms}

The wear mode of the P3C coating was dominated by the erosion of matrix leading to carbide pullout. The wear debris which contained a mixture of ball and coating material dominated the wear process in three-body abrasion. Transfer film from ball to coating surface was also observed in test couples. The severity of abrasive wear either in two-body or three-body abrasion varied between the test couples.

4.4.1.1 Tests with Steel Ball Couples Figure 10 shows the SEM and EDX observations of the wear scars of test couples which involved steel ball as the counterbody. Figure 10a shows the presence of transfer film, which was dominantly $\mathrm{Fe}$ and $\mathrm{O}$ due to the flash temperatures and transfer of $\mathrm{Fe}$ from the ball material. A typical comparison of tribofilm composition within the wear track for steel test couples is shown in Fig. 10a, c, f. Figure 10a also shows some erosion of matrix exposing the carbides. After the HIPing post-treatment (Fig. 10b, c), the mechanism of transfer film remains (Fig. 10c), but the erosion of matrix is more localized within the marked area in the wear track (Fig. 10b). Comparison of Fig. 10a, b, c with Fig. 10d indicates much better retention of matrix phase protecting the carbides. This is consistent with the relatively lower coating wear loss for P2C coating against the steel ball shown in Fig. 15b; however, consequently there was a relatively higher ball wear rate as shown in Fig. 15a. After HIPing (P2C-HIP), the mechanism of transfer film (Fig. 10f) and matrix retention (Fig. 10g) remains; however, a delamination-type failure increases the relative coating wear rate as shown in Fig. 10e. The tribofilm formed during sliding wear is dynamic and goes through a process of film generation and removal during wear as previously discussed [22]. Removal of film can occur due to removal of coating material or due to shear stress. This led to localized removal of tribofilm as observed in Fig. 10b, c, f. However, a corresponding relative decrease in the ball wear rate (Fig. 15a) improves the total wear rate after the HIPing post-treatment. For the case of HVOF-JK coatings (as-sprayed P3C), the erosion of metal matrix was severe as indicated in Fig. 10h, exposing the carbides; however, the relatively larger carbide size increased the ball wear rate for P3C-steel ball test couples (Fig. 15a). Further details of the wear mechanisms can be seen in previous publication $[22,23]$.

4.4.1.2 Tests with Ceramic Ball Couples For the case of $\mathrm{Si}_{3} \mathrm{~N}_{4}$ ball, the wear mechanism was similar to that of steel ball but with the absence of a dominant tribofilm on the coating surface (Fig. 11). This is attributed to the tribochemistry of $\mathrm{Si}_{3} \mathrm{~N}_{4}$ which results in relative softening of the surface [45]. This could explain that despite similar hardness and fracture values of $\mathrm{Si}_{3} \mathrm{~N}_{4}$ and $\mathrm{WC}-\mathrm{Co}$ balls (Table 9), the ball wear rate of $\mathrm{Si}_{3} \mathrm{~N}_{4}$ ball was significantly higher and comparable to that of the steel ball (Fig. 15a). The EDX analysis of the wear track on the ball surface did not indicate the presence of $\mathrm{WC}$ or $\mathrm{Co}$, indicating that there was no transfer layer from the coating surface. Hence, the 

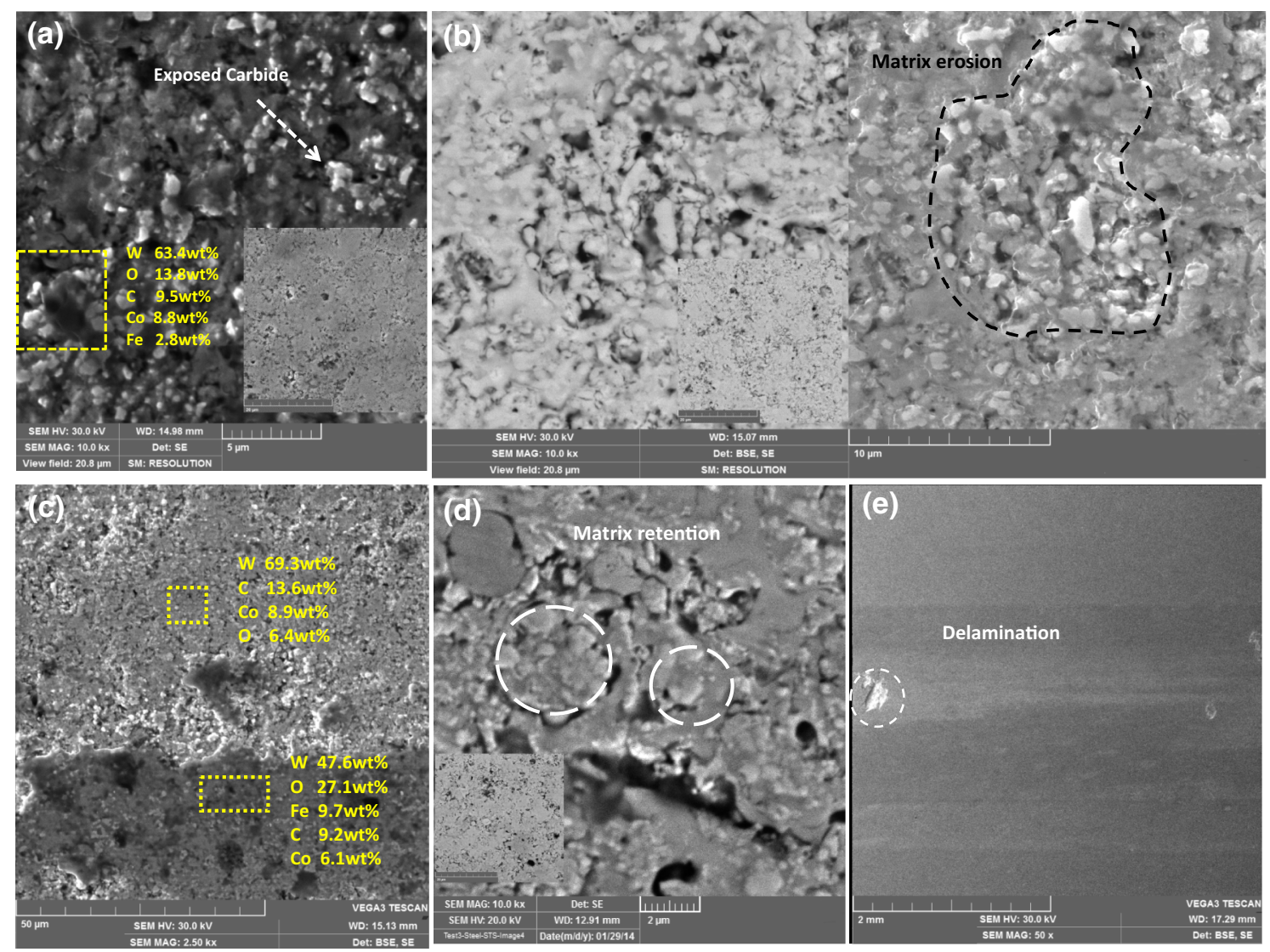

(e)
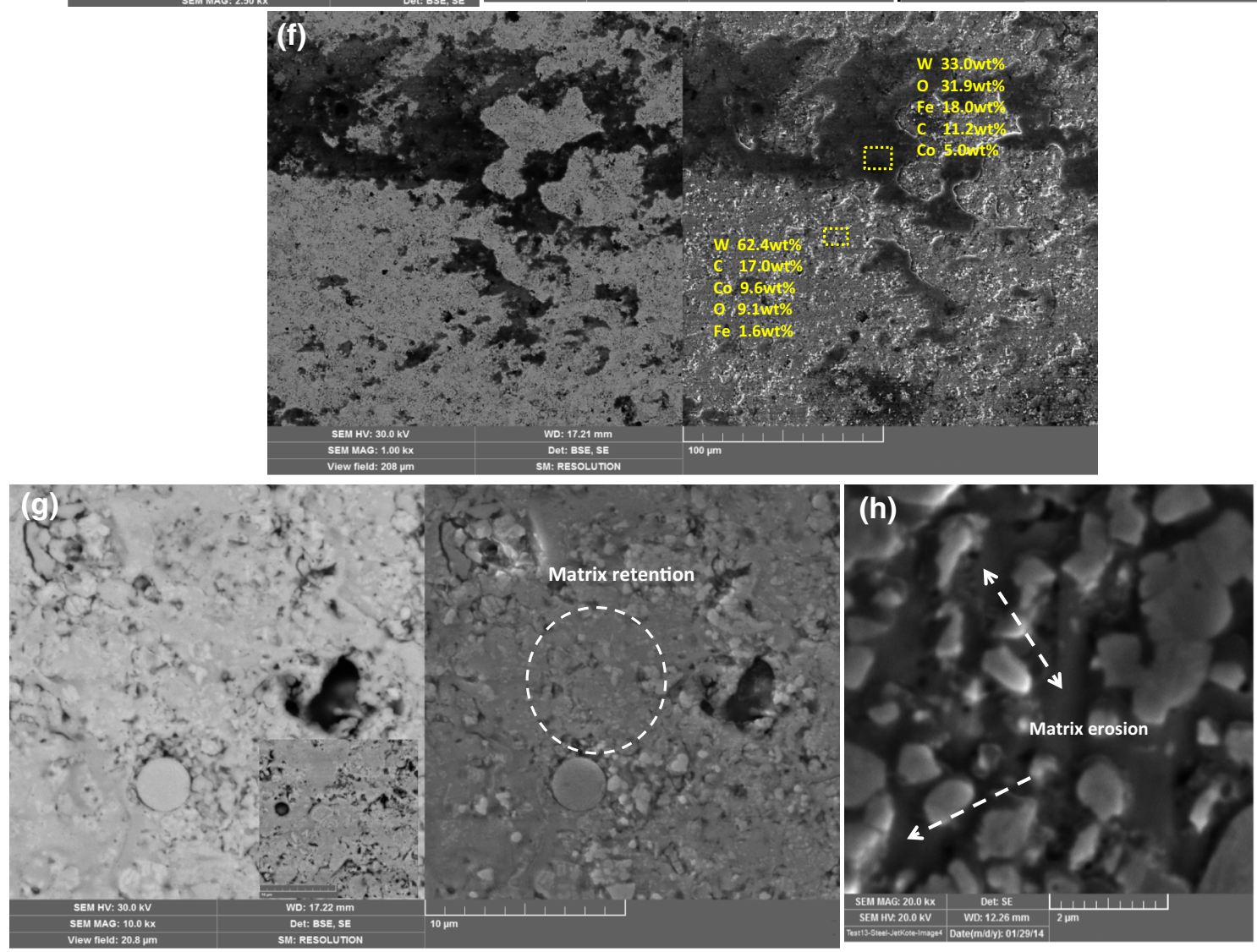
4 Fig. 10 SEM micrograph of stainless steel (440C) couple wear track a P1C. b, c P1C-HIP. d P2C. e-g P2C-HIP. h P3C. Inserted windows in $\mathbf{a}, \mathbf{b}, \mathbf{d}, \mathbf{g}$ represent typical unworn surface with the scale bar of $20 \mu \mathrm{m}$

mechanism of ball wear for the $\mathrm{Si}_{3} \mathrm{~N}_{4}$ ceramic was different in comparison with the WC-Co and the steel ball, which does not facilitate a robust tribofilm on the coating surface. Further details of these tribo-chemical reactions associated with the $\mathrm{Si}_{3} \mathrm{~N}_{4}$ ceramic can be seen in a recent detailed review [45]. As the tribofilm protects the coating surface, its absence in the case of ceramic ball couples resulted in the highest coating loss for all cases (Fig. 15b) when compared to the steel and $\mathrm{WC}-\mathrm{Co}$ ball materials. The absence of the tribofilm also resulted in severe plastic deformation of the metal matrix resulting in matrix extrusion and carbide pullout as shown in Fig. 11a, b. After the HIPing post-treatment, there was some indication of coating delamination as marked in Fig. 11c.

4.4.1.3 Tests with WC-Co Ball Couples Despite the higher hardness and modulus of $\mathrm{WC}-\mathrm{Co}$ ball as the
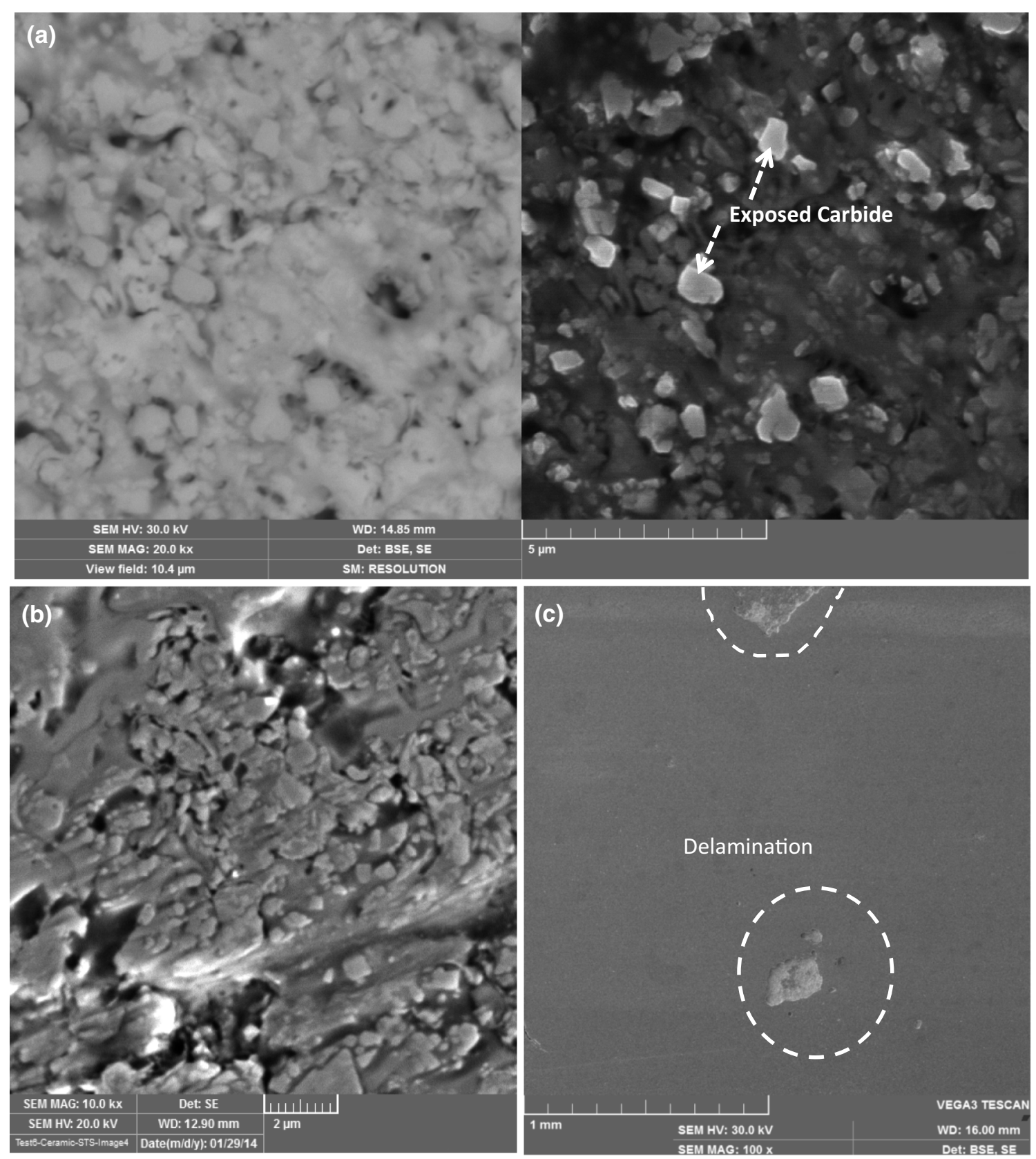

Fig. 11 SEM micrograph of ceramic $\left(\mathrm{Si}_{3} \mathrm{~N}_{4}\right)$ couple wear track a P1C. b P2C. c P2C-HIP 


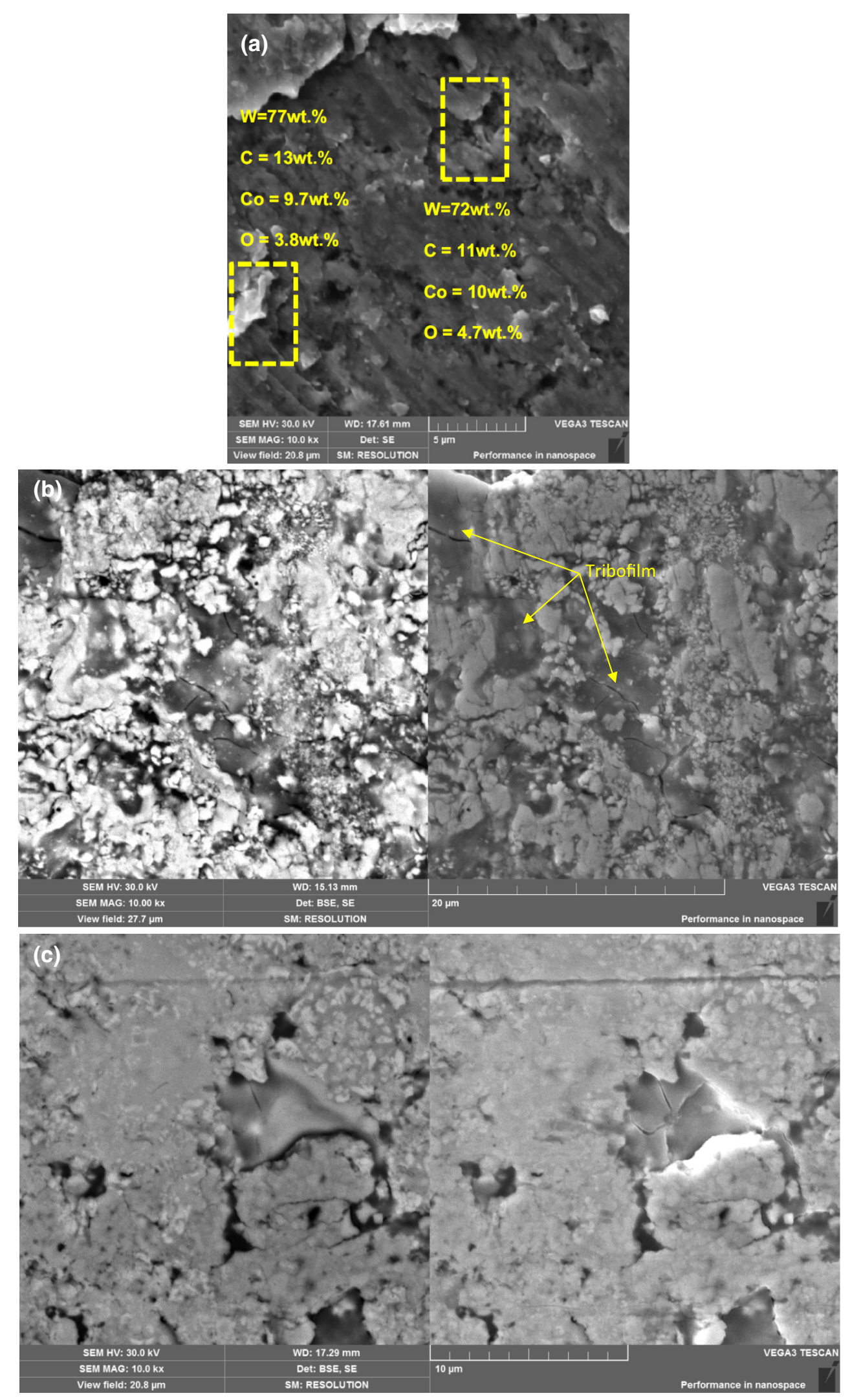

Fig. 12 SEM micrograph of WC-6Co couple wear track a P1C. b P2C. c P2C-HIP 
counterbody, both the coating and ball wear rates were the lowest for this test couple when compared to the steel and ceramic balls (Fig. 15a, b). Two factors are attributed to this lower wear rate, (1) the presence of tribofilm due to oxidation under flash temperature and some transfer material on the coating surface as shown Fig. 12, and (2) the lower content of ball wear debris reducing the overall wear in three-body abrasion. Previous studies have shown that the W-based oxidized tribofilm is formed by comminution and tribo-oxidation of very small fragments of coating material, coming from the removal of matrix together with the WC grains [46]. It is also reported that the good lubrication properties of $\mathrm{WC}-\mathrm{Co}$ coatings are due to the oxides formed, mainly $\mathrm{CoO}$ and $\mathrm{WO}_{3}$, the latter having good lubricant properties [36, 37, 47]. Moreover, this tribofilm also fills the cavities in the worn coating as shown in Fig. 10b, c, which is different to the tribofilm observed for the steel ball couples where the film grows on top of the coating surface. Further details of the wear mechanism with WC-Co ball couples can be seen in earlier investigation [22].

In summary,

1. The total wear rate of both S-HVOF as-sprayed and HIPed coatings was higher than that of the HVOF coatings against steel and ceramic test couples. The performance of S-HVOF coatings was slightly better for the WC-Co ball test couples. The relative performance of S-HVOF coatings deposited from powder P1C was better than P2C. HIPing post-treatment improved the total wear rate performance for both S-HVOF coatings.

2. In terms of coating wear rate, the trend is similar to that of total wear rate except for steel ball couples where HIPing post-treatment of S-HVOF coatings shows an increase in wear rate. Previous research has shown that the increase in elastic modulus after HIPing post-treatment also results in an increase in fracture toughness of WC-Co coatings [15, 16, 39]. There was also an increase in hardness after HIPing due to crystallization and densification. As expected, the coating wear rate is lower after HIPing especially for the harder and tougher counterbody of $\mathrm{Si}_{3} \mathrm{~N}_{4}$ and WCCo. This is despite the indication of some delamination wear of the coatings for all test couples. However, the matrix erosion was more pronounced for the case of steel ball couples, which is attributed to the localized removal of tribofilm during the test (Fig. 10b, c). This could have led to higher wear rate for the HIPed S-HVOF coatings against steel ball couples. (a)

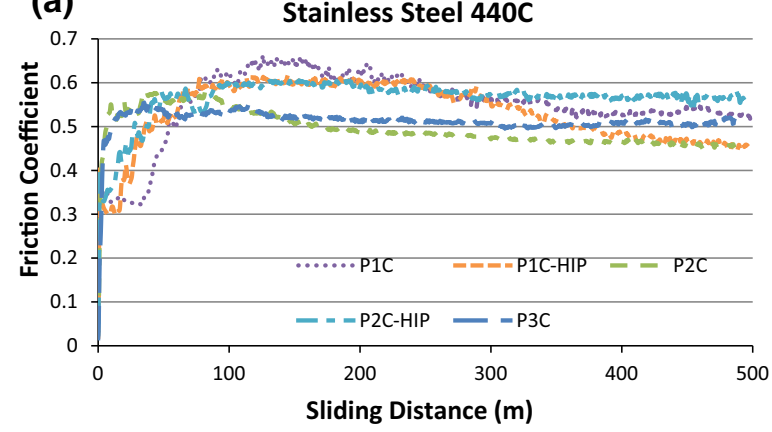

(b) Ceramic $\mathrm{Si}_{3} \mathrm{~N}_{4}$

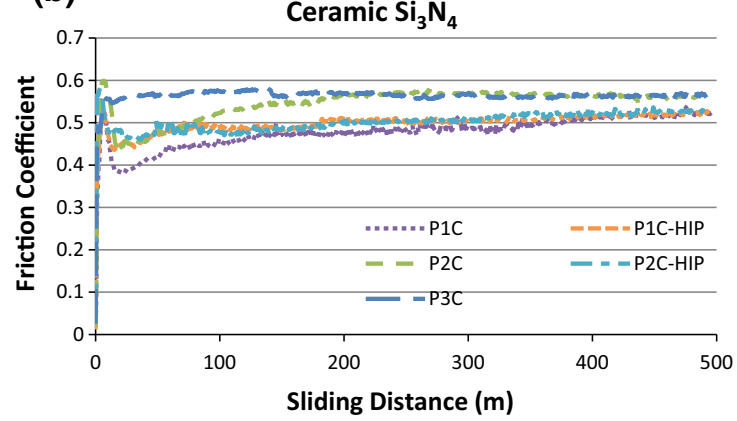

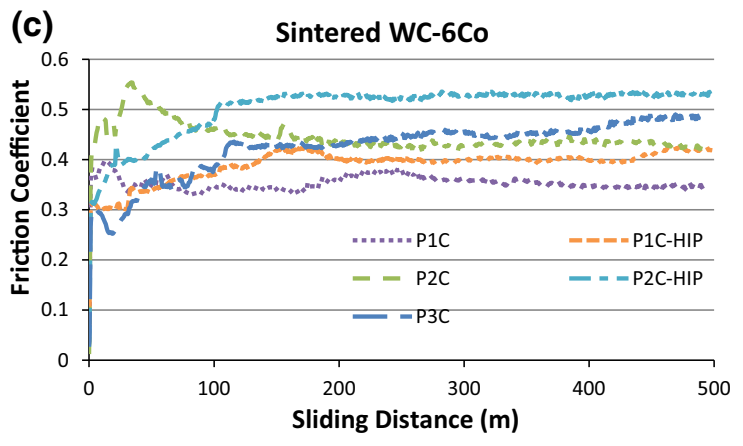

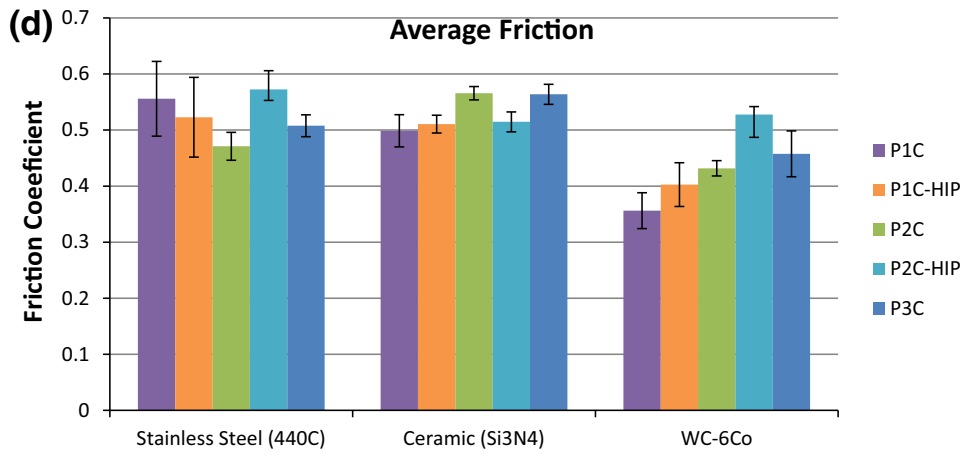

Fig. 13 Average friction coefficient against sliding distance of $500 \mathrm{~m}$ with $25 \mathrm{~N}$ normal load for all coatings against sintered a stainless steel (440C), b ceramic $\left(\mathrm{Si}_{3} \mathrm{~N}_{4}\right)$, c WC-6Co and $\mathbf{d}$ average coefficient of friction for last $300 \mathrm{~m}$ of sliding distance for coating-ball material pairs 
Fig. 14 a Average nanoindentation hardness values for cross section from all coatings and $\mathbf{b}$ average nanoindentation elasticity values for cross section from all coatings (Berkovich indenter)
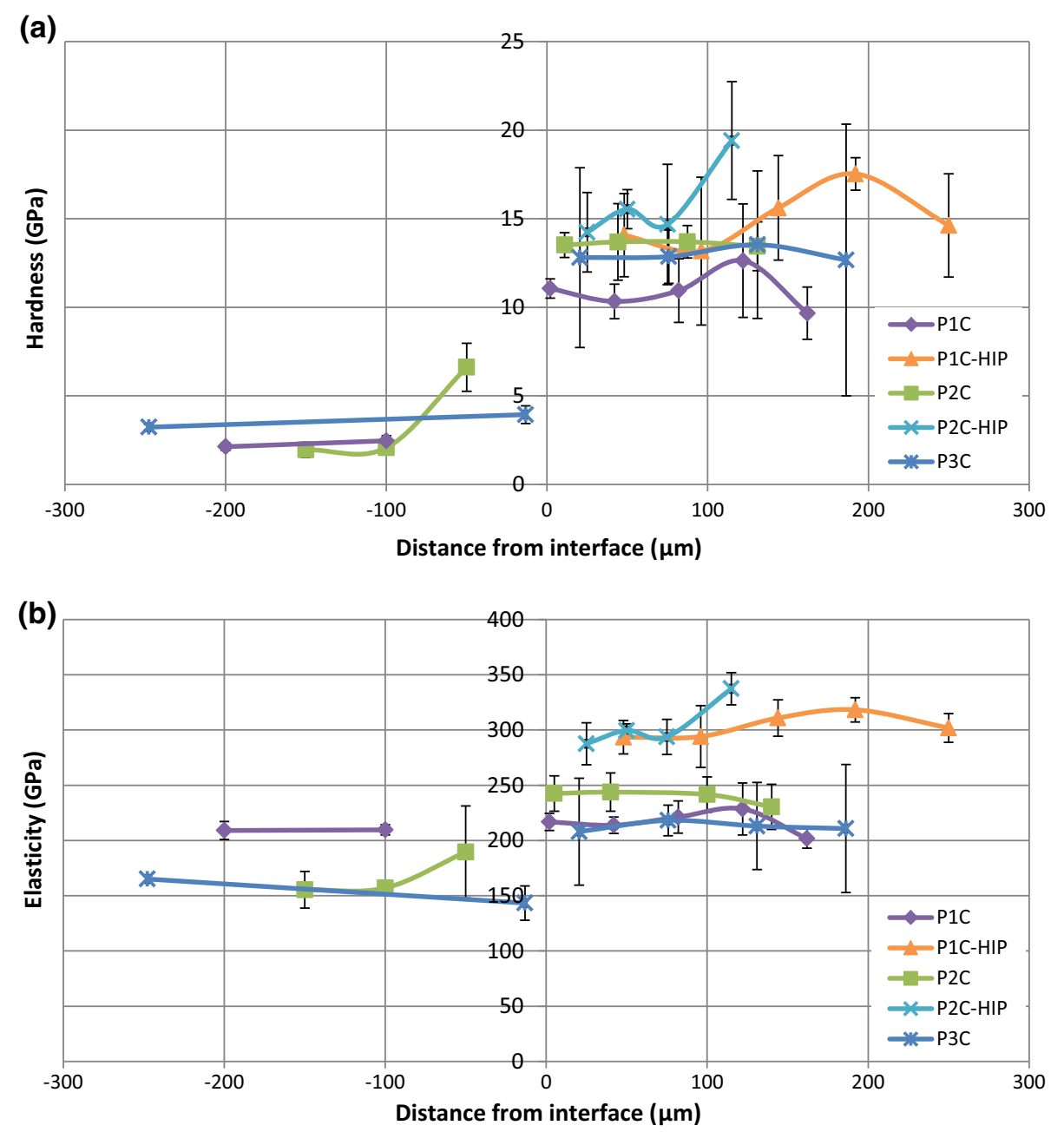

3. The coating wear rate was highest for the ceramic ball couples, which is attributed to the lack/absence of tribofilm on the coating surface. The tribofilm for the WC-Co ball couples filled the worn surface in the wear track and provided more consistent protection against wear. For the steel ball couples, there was evidence of tribofilm formation and also localized removal of the tribofilm as discussed above.

An interpretation of the severity of coating wear changes after the HIPing post-treatment can be considered by comparing the average depth and width of wear scars. This is summarized in Fig. 16. The wear volume loss is based on the calculation of the width and depth of the wear track. The width of the wear track was dependent on the ball wear rate, which is expected as when the ball wears, it also widens the coating wear track. The depth of wear scar represents the groove of coating wear. This can be understood in the sense that a wider shallower wear scar will give the same coating volume loss as a narrower but deeper wear scar. However, the former is dominated by ball wear and latter with coating wear. This difference is illustrated in Fig. 16 which indicates higher averaged maximum wear depth of 4 and $7 \mu \mathrm{m}$ for the P1C as-sprayed coating couple against $\mathrm{Si}_{3} \mathrm{~N}_{4}$ and WC-Co ball couples, respectively. Comparative values for the P1C HIPed coating in Fig. 16 are approximately $3 \mu \mathrm{m}$ and $0.4 \mu \mathrm{m}$, respectively. The width of the wear track for the $\mathrm{Si}_{3} \mathrm{~N}_{4}$ and WC-Co ball couples is, however, significantly different which contributes to the changes in the total coating volume loss. The difference in the depth and width of the wear track of WC-Co ball couple is rather subtle which indicates the role of debri entrapment in deeper but relatively narrower wear track. During the reciprocating motion in the ball-on-plate tests, the direction of sliding motion reverses at the ends of the wear track, and the velocity is constantly changing with maximum velocity in the center of the wear track length. These velocity changes influence the debri entrapment in the contact region. This role of the debri entrapment in the contact region, along with the size and composition of the wear debri and the shape of wear track for different ball couples, results in a dynamic system, making debri interaction in three-body abrasion an essential part of the wear system. 
(a)

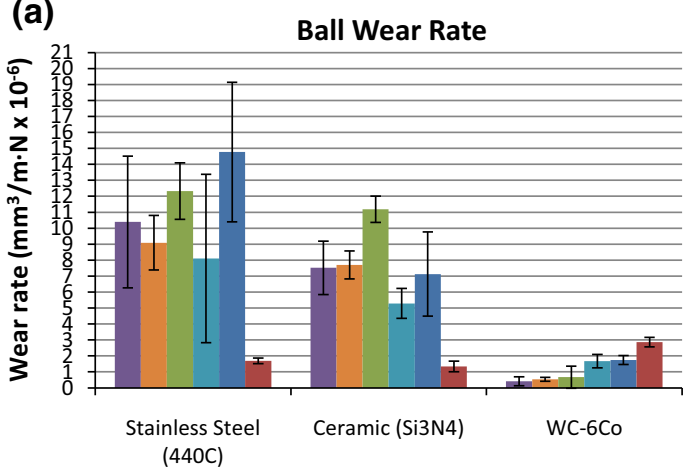

(c)

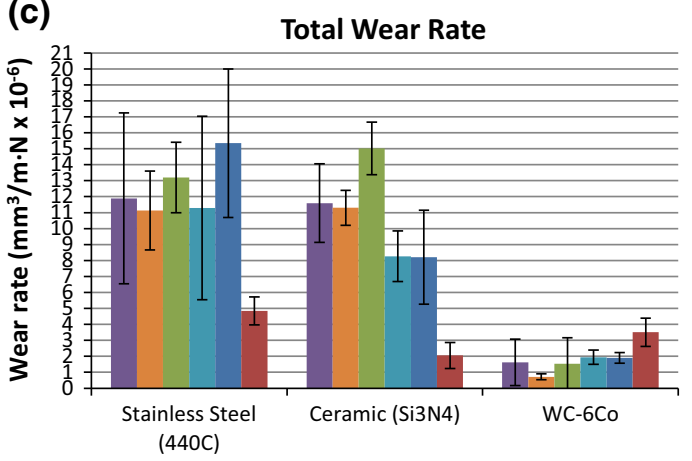

(b) Coating Wear Rate

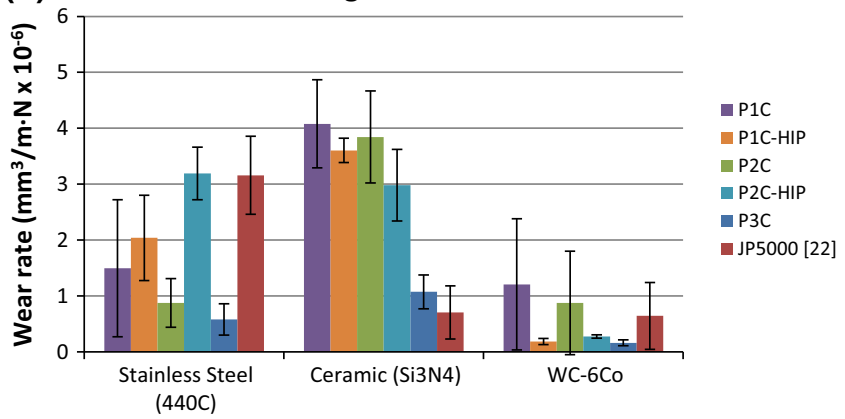

(d)

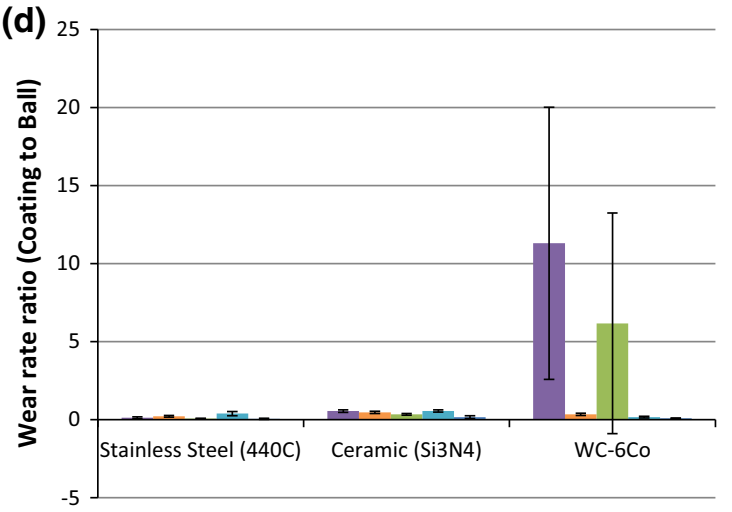

- P1C - P1C-HIP $\mathrm{P} 2 \mathrm{C}$ - P2C-HIP - $\mathrm{P} 3 \mathrm{C}$

Fig. 15 Column plots of wear rate. a Ball wear rate, $\mathbf{b}$ coating wear rate, $\mathbf{c}$ total wear rate (ball + coating) and $\mathbf{d}$ wear rate ratio (coating to ball)

Table 8 Mechanical properties of the coatings used for mathematical modeling

\begin{tabular}{llllll}
\hline Coating & P1C & P1C-HIP & P2C & P2C-HIP & P3C \\
\hline Nanohardness $(\mathrm{GPa})$ & $10.93 \pm 1.10$ & $15.00 \pm 1.67$ & $13.59 \pm 0.13$ & $15.97 \pm 2.36$ & $12.97 \pm 0.38$ \\
Elastic modulus $(\mathrm{GPa})$ & $216.44 \pm 9.93$ & $303.75 \pm 10.79$ & $239.57 \pm 6.16$ & $304.58 \pm 22.43$ & $209.62 \pm 2.54$ \\
$\mathrm{~K}_{1 \mathrm{c}}\left(\mathrm{MPa} \mathrm{m}{ }^{1 / 2}\right)$ & $3^{*}$ & $4^{*}$ & $3^{*}$ & $4 *$ & 5.2 \\
\hline
\end{tabular}

* Approximated from Ref [33]

Table 9 Mechanical properties for ball material used for mathematical modeling

\begin{tabular}{lccl}
\hline Ball & Steel—440C & Ceramic $\left(\mathrm{Si}_{3} \mathrm{~N}_{4}\right)$ & $\begin{array}{l}\mathrm{WC}- \\
6 \mathrm{Co}\end{array}$ \\
\hline Vickers hardness & 400 & 1550 & 1650 \\
Elastic modulus $(\mathrm{GPa})$ & 210 & 320 & 580 \\
$\mathrm{~K}_{1 \mathrm{c}}\left(\mathrm{MPa} \mathrm{m}{ }^{1 / 2}\right)$ & 95 & 6 & 7.8 \\
\hline
\end{tabular}

4.4.1.4 Friction Response The friction response varied between the three ball couples with no consistent trend when comparing coatings. Test couples involving WC-Co ball generally indicated relatively lower friction coefficient values, followed by the steel and ceramic balls. Tests which involved WC-Co balls (Fig. 13) with HIPed coatings (P1C-HIP and P2C-HIP) indicate relatively higher averaged friction coefficient values when compared to the as-sprayed coatings (P1C, P2C). No definite trend of HIPing on the friction coefficient was observed for test couples which involved the steel and $\mathrm{Si}_{3} \mathrm{~N}_{4}$ balls (Fig. 13). The standard deviation of friction coefficient values was lowest involving $\mathrm{Si}_{3} \mathrm{~N}_{4}$ balls when compared to the steel and WC-Co balls. This can be attributed to the absence of tribofilm for the $\mathrm{Si}_{3} \mathrm{~N}_{4}$ ball tests, when compared to the constant buildup and removal of tribofilm in the steel and WC-Co ball tests. Although the presence of tribofilm reduced averaged friction coefficient for the case of $\mathrm{WC}-$ Co ball test couples, the difference between the steel and $\mathrm{Si}_{3} \mathrm{~N}_{4}$ ball test couples is not subtle. This is attributed to the presence of $\mathrm{Fe}$ in the oxidized tribofilm for the tests involving steel ball couple, which will induce plasticity as an energy dissipation mechanism in the tribofilm and also ball material when compared to brittle $\mathrm{Si}_{3} \mathrm{~N}_{4}$ and WC-Co balls. 
Fig. 16 Wear track profiles for $\mathrm{P} 1 \mathrm{C}$ and $\mathrm{P} 1 \mathrm{C}-\mathrm{HIP}$ coatings for a ceramic $\mathrm{Si}_{3} \mathrm{~N}_{4}$ ball couple, b WC-6Co ball couple
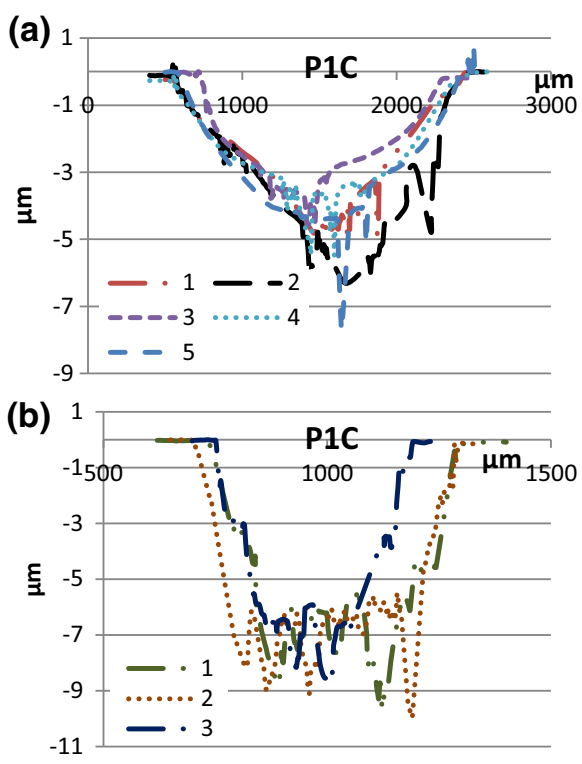
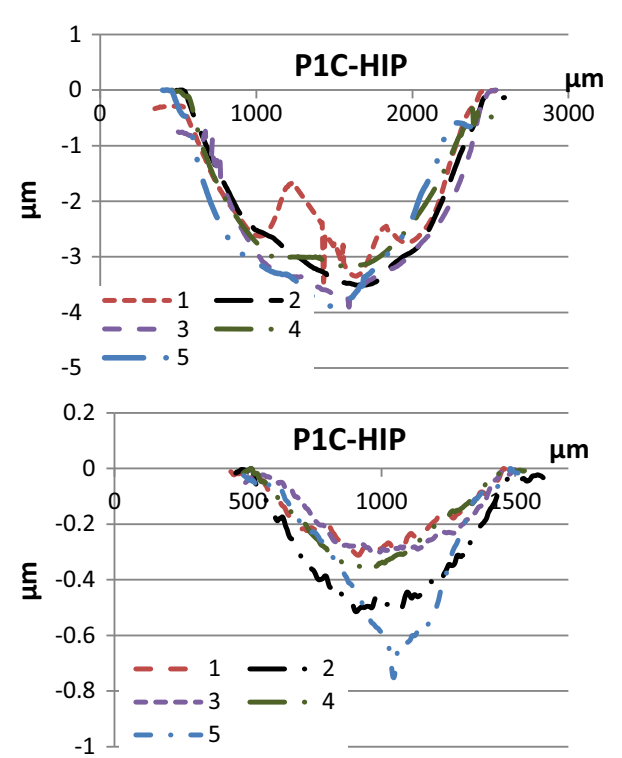

\subsubsection{Mathematical Models of Wear Rate}

Wayne et al. [48] had indicated that the abrasive wear rate for a range of sintered $\mathrm{WC}-\mathrm{Co}$ cermets is approximately proportional to a function of $D_{\mathrm{WC}} /\left(K_{\mathrm{IC}}^{3 / 8} \mathrm{H}^{1 / 2}\right)$, where $D_{\mathrm{WC}}$ is the average WC grain size, $\mathrm{H}$ Knoop microhardness of WC-Co, and $K_{\text {IC }}$ its fracture toughness. This correlation was based on the wear mechanism which initiated from the cobalt extrusion followed by the carbide removal. In the current investigation, although the average carbide size varied between the S-HVOF and HVOF coatings, the proportionality of wear rate to $D_{\mathrm{WC}} /\left(K_{\mathrm{IC}}^{3 / 8} \mathrm{H}^{1 / 2}\right)$ was not observed. This is attributed to the microstructure of assprayed thermal spray coatings which show a lamella structure and their different phase composition when compared to the sintered $\mathrm{WC}-\mathrm{Co}$, and to the changes in the wear mechanism when considering the steel, $\mathrm{Si}_{3} \mathrm{~N}_{4}$ and WC-Co ball test couples. Such relationships normally do not follow beyond the specific tribological test conditions which normally involve the same type of test couples. In the current investigation, the changes in ball material and hence the changes in wear mechanism(s) added additional complexity to the task of relating mechanical properties to the tribological wear performance. Wood [5] had also recently indicated this complexity and indicated that in the case of thermal spray coatings, the dependencies of wear rate on the binder metal, porosity, hardness and Young's modulus were not found.

In the current investigation, as the ball material varies significantly in terms of its relative hardness $\left(H_{\text {ball }}\right)$, Young's modulus $\left(E_{\text {ball }}\right)$, fracture toughness $\left(\mathrm{K}_{\mathrm{IC} \text { ball }}\right)$ when compared to the respective coating hardness $\left(H_{\text {coating }}\right)$, Young's modulus $\left(E_{\text {coating }}\right)$ and fracture toughness $\left(K_{\mathrm{IC} \text { coating }}\right)$, a linear relationship satisfying all tribological conditions considered in this investigation was not achievable (Tables 8, 9). Instead, an effort was made to incorporate the influence of critical factors such as:

1. normally in sliding wear applications, the hardness of the harder counterface is used. However, in the current investigation of HVOF coatings, as the relative ball hardness is lower for the steel and higher for the WC$\mathrm{Co}$ and $\mathrm{Si}_{3} \mathrm{~N}_{4}$, an attempt is made to incorporate the influence of the ball to the coating hardness ratio $\left(H_{\text {ball }} /\right.$ $H_{\text {coating }}$,

2. as the ball diameter was relatively smaller for the $\mathrm{WC}-$ Co ball in comparison with the steel and $\mathrm{Si}_{3} \mathrm{~N}_{4}$ ceramic balls, and as the values of the elastic properties varied between the various test couples, a variable based upon the Hertzian contact stress $\left(P_{\mathrm{o}}\right)$ was introduced to cater for the differences in the ball geometry and elastic properties of test couples,

3. fracture of surfaces inevitably leads to the formation of wear debris so the $K_{\mathrm{IC}}$ of the coatings was considered as another variable.

Tables 8 and 9 provide the physical parameters for coating and ball material for establishing the semiempirical models of wear rate. The $K_{\text {IC }}$ of coating was approximated from a previous investigation by the authors [39], keeping in view the carbon deficiency of S-HVOF coatings; hence, a lower-bound values are used in this analysis. The difficulty in measuring the fracture toughness of brittle thermal spray coatings has previously been discussed $[33,38]$. The fracture toughness of the ball material was not directly included in this analysis as for the steel and WC-Co balls, fracture dominated wear mechanism was not observed. The fracture response of the hydrated $\mathrm{Si}_{3} \mathrm{~N}_{4}$ tribofilm was also not clear to be included as a variable in this analysis. The 
above variables being catered for most of the wear mechanisms, the lack of data on the yield strength of hydrated $\mathrm{Si}_{3} \mathrm{~N}_{4}$ film meant that plasticity could only be introduced indirectly in the form of hardness ratio. It may be possible to investigate the mechanical properties of hydrated $\mathrm{Si}_{3} \mathrm{~N}_{4}$ film using nanoindentation and nanoscratch tests $[49,50]$.
Similarly, the carbide size and carbon loss in the coating microstructure were indirectly used in the form of coating fracture toughness values.

Figure 17 provides some basic correlations between the tribological and structural (microstructure and mechanical) properties. Figure 17a shows the correlation between the
Fig. 17 Wear rate versus the mechanical properties of the ball and coating materials

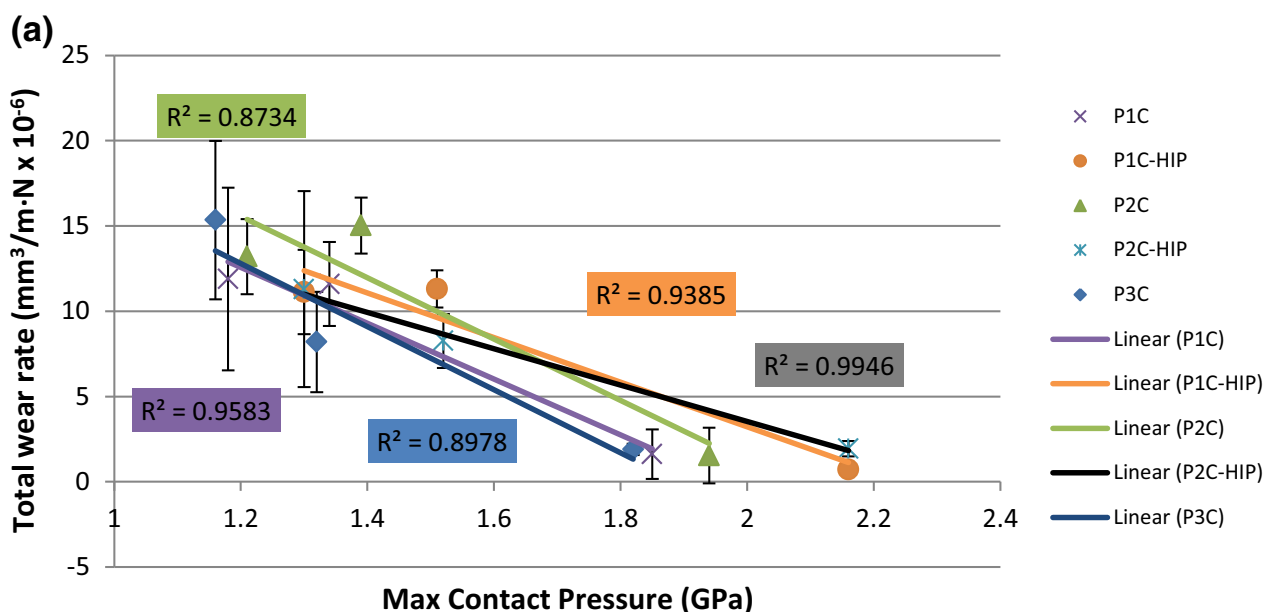

(b)

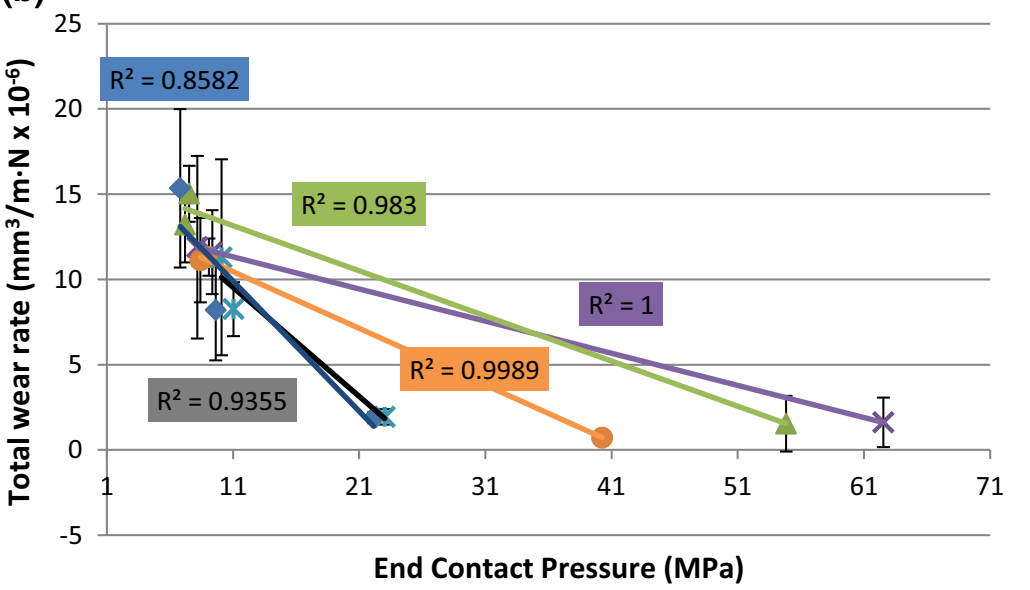

$\times \quad \mathrm{P} 1 \mathrm{C}$

- P1C-HIP

$\triangle \mathrm{P} 2 \mathrm{C}$

* P2C-HIP

- $\mathrm{P} 3 \mathrm{C}$

Linear (P1C)

Linear (P1C-HIP)

Linear (P2C)

Linear (P2C-HIP)

Linear (P3C)

(c)

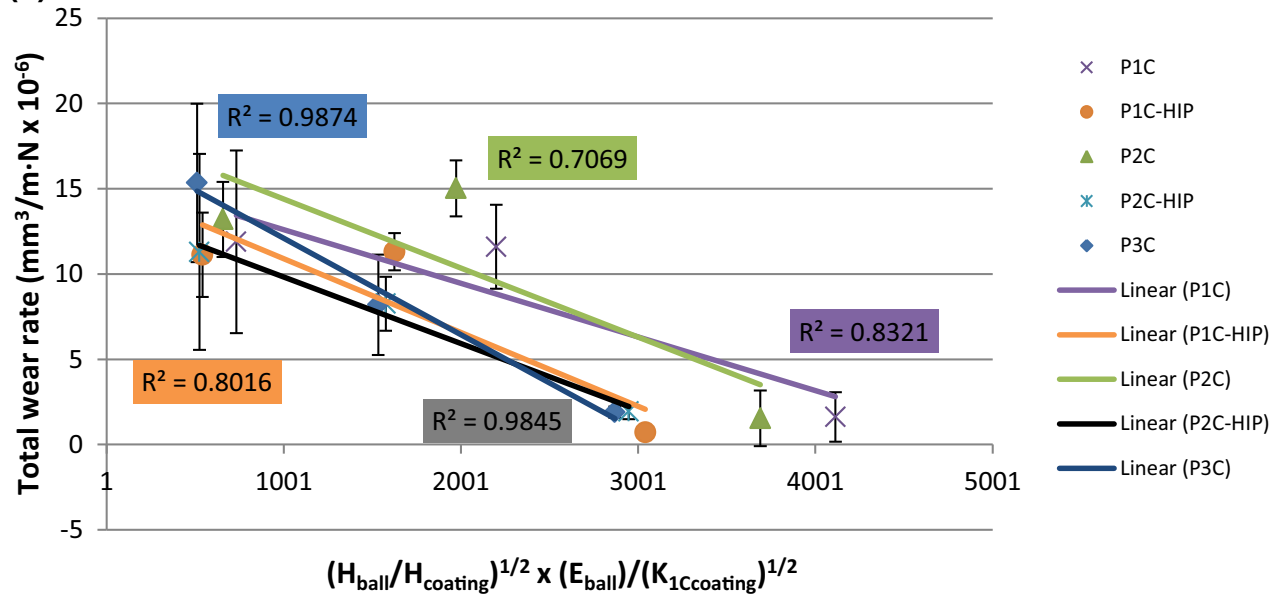


Fig. 17 continued (d)

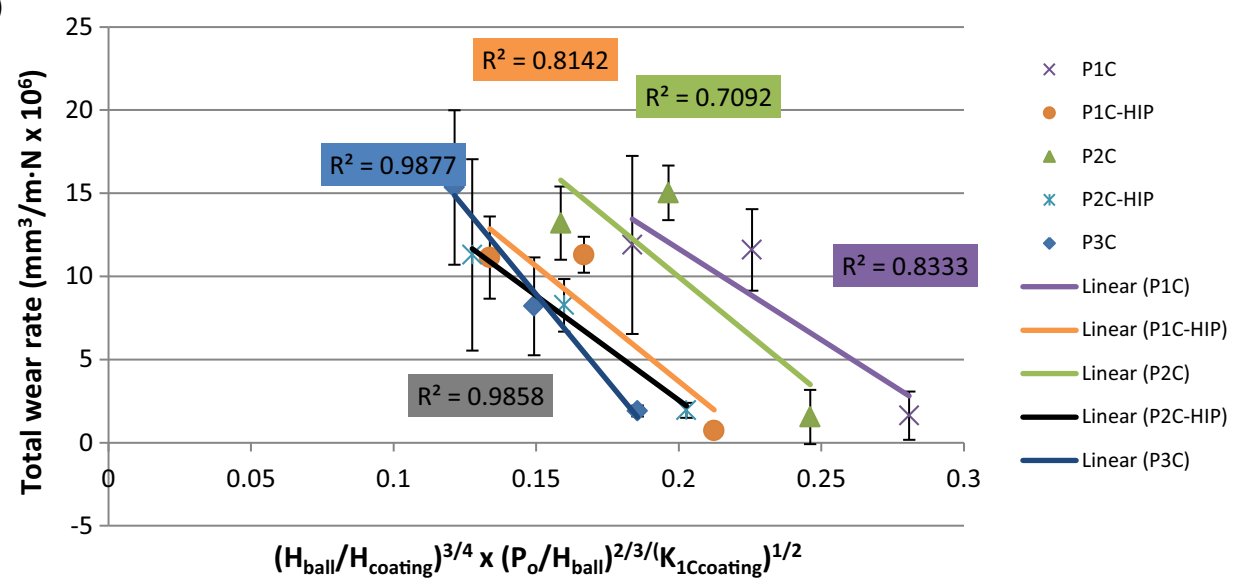

(e)
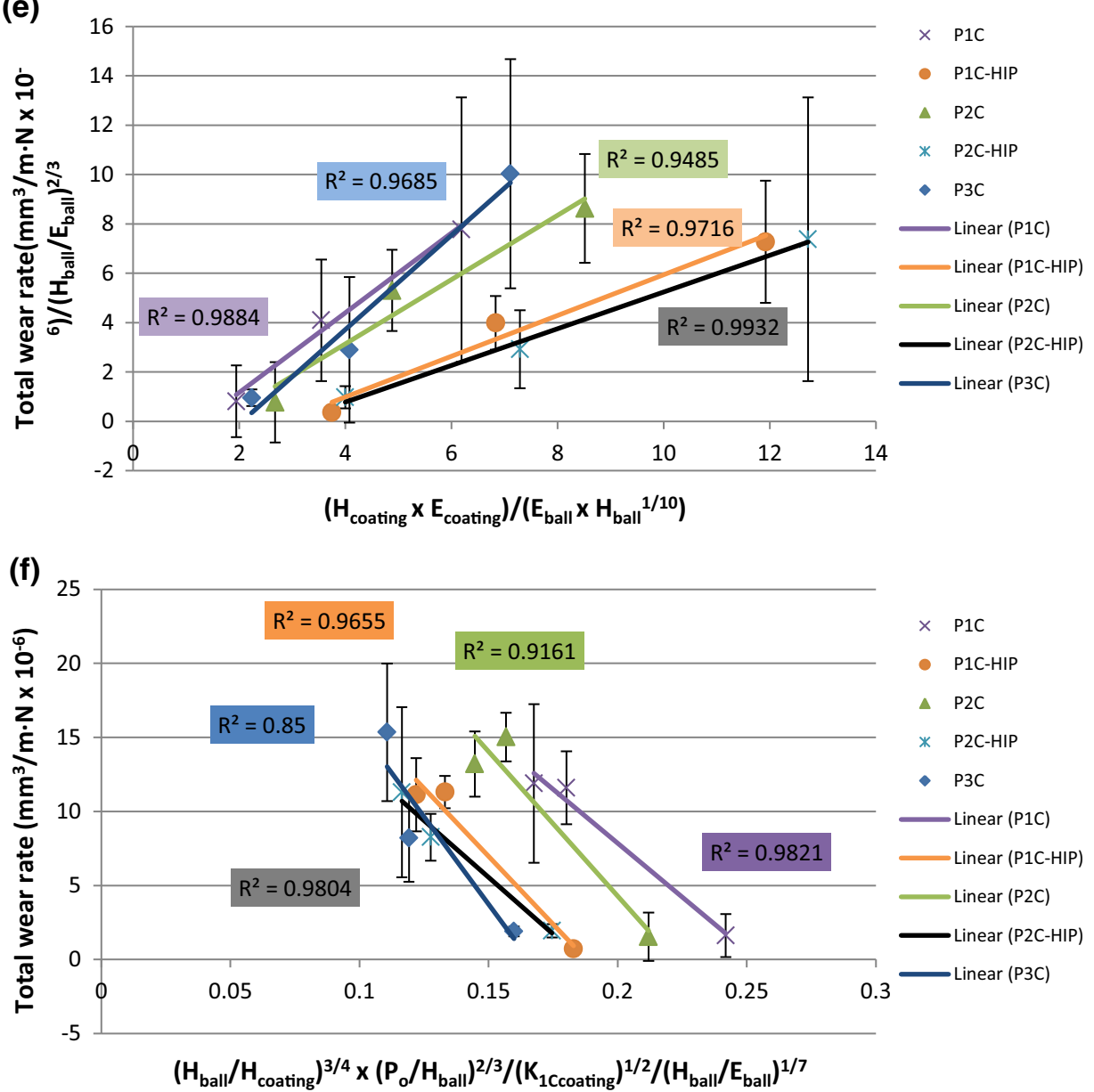

wear rate and Hertz contact stress $\left(P_{\mathrm{o}}\right)$ at the start of the wear test. There exists a correlation between the total wear rate and $P_{\mathrm{o}}$. The regression is better for the HIPed coatings. Figure 17b shows the relationship between the total wear rate and average contact pressure at the end of the wear test. This end contact pressure was calculated from the dimensions of the ball wear scar at the end of the tests. This correlation shows an almost linear fit between the total wear rate and the end contact pressure for the S-HVOF coatings. However, the use of end contact pressure in tribological design process limits its use as it requires experimental wear data, which will not be required for the maximum contact pressure correlation shown in Fig. 17a.

Figure $17 \mathrm{c}$ shows the total wear rate correlation with the $\sqrt{\frac{H_{\text {ball }}}{H_{\text {caating }}}} \times E_{\text {ball }} / \sqrt{K_{\text {IC coating }}}$ variable. In this correlation, the linear fit is within the standard deviation of the experimental wear rates for the HVOF-JK coatings, whereas for 
the case of S-HVOF coatings (P1C, P2C), the linear function fits with less accuracy. However, the HIPed coatings (P1C-HIP, P2C-HIP) correlation improves. A similar trend can be observed in Fig. 17d which shows a modified correlation of the total wear rate with $\left(\frac{H_{\text {ball }}}{H_{\text {coating }}}\right)^{3 / 4}$ $\times\left(\frac{P_{\mathrm{O}}}{H_{\text {ball }}}\right)^{2 / 3} / \sqrt{K_{\text {ICcoating. }}}$. This correlation provides a similar fit for both the S-HVOF (P1C, P1C-HIP, P2C, P2C-HIP) and HVOF-JK (P3C) coatings. Although these correlations fall within the standard deviation of the experimental wear rates of the sliding wear tests, a better fit could not be achieved if carbide size was introduced as a variable, as proposed by Wayne et al. [48].

An almost linear correlation existed for all test conditions considered in this investigation for the case of total wear $\operatorname{rate} /\left(H_{\text {ball }} / E_{\text {ball }}\right)^{2 / 3}$ versus $\left(H_{\text {coating }} \times E_{\text {coating }}\right) /$ $\left(E_{\text {ball }} \times H_{\text {ball }}\right)^{1 / 10}$ as shown in Fig. 17e. This indicates that the wear mechanism of coating and ball couples was more dominated by the elastic and plastic deformation instead of fracture. This correlation also clearly differentiates between the wear rates of as-sprayed (P1C, P2C, P3C) and HIPed S-HVOF (P1C-HIP, P2C-HIP) coatings. A correlation of total wear rate versus $\left(H_{\text {ball }} / H_{\text {coating }}\right)^{3 / 4} \times\left(P_{\mathrm{o}} /\right.$ $\left.H_{\text {ball }}\right)^{2 / 3} /\left(K_{\text {ICcoating }}\right)^{1 / 2} /\left(H_{\text {ball }} / E_{\text {ball }}\right)^{1 / 7}$ is shown in Fig. $17 \mathrm{f}$. This correlation includes the fracture toughness of the coating material and provides an almost linear fit to the wear data. The data were also analyzed for correlations relating to specific ball and coating wear rates instead of total wear rates.

The semiempirical mathematical model of wear rate presented in this work relates to the sliding wear conditions which are similar to that of ASTM G133 (procedure A). This study therefore provides a benchmark for future analysis. However, these correlations need to be further refined by considering the changes in normal load and sliding speed. Similarly with further testing, it may be possible to refine these correlations to include lubricated test conditions. This will also help develop the basis for numerical models of sliding wear for WC-Co coatings [51].

\section{Conclusions}

1. As spraying of aqueous WC-Co suspensions was connected with a significant carbon loss, microstructural investigations of as-sprayed and HIPed S-HVOF coatings indicated crystallization of nanocomposite phases after the HIPing post-treatment and the presence of $\mathrm{W}, \mathrm{WC}$ and eta-phases $\left(\mathrm{M}_{6} \mathrm{C}, \mathrm{M}_{12} \mathrm{C}\right)$. Thermodynamic calculations have shown that metallic tungsten appears as an equilibrium phase for higher carbon loss. The TEM investigations indicated that the size of these grains ranged from 20 to $200 \mathrm{~nm}$.

2. The hardness and elastic modulus of S-HVOF coatings were comparable with conventional HVOF-JK coatings. The hardness and modulus of S-HVOF coatings further increased after the HIPing post-treatment. This was attributed to the crystallization and improved bonding of microstructural phases.

3. The wear mechanism against the three ball couples was dominated by the extrusion of metal matrix followed by carbide pullout. There was some evidence of delamination failure for the HIPed S-HVOF coatings.

4. The total wear rate of S-HVOF coatings was strongly dependent on the counterbody material, and in the case of WC-Co counterbody comparable to the HVOF-JK coatings. The total wear rate was dominated by the ball wear rate. Based on the average depth of wear scar, the severity of wear reduced after the HIPing posttreatment in many cases.

5. The total wear rate of both S-HVOF as-sprayed and HIPed coatings was higher than that of the Jet Kote and JP5000 coatings against steel and ceramic test couples. The performance of S-HVOF coatings was slightly better for the WC-Co ball test couples. HIPing post-treatment improved the total wear rate performance for both S-HVOF coatings.

6. In terms of coating wear rate, the trend is similar to that of total wear rate except for steel ball couples where HIPing post-treatment of S-HVOF coatings shows an increase in wear rate. The coating wear rate was highest for the ceramic ball couples, which is attributed to the lack of tribofilm in this test couple.

7. Mathematical relationships indicate that the correlations based on the contact stress, hardness ratio and fracture toughness can provide a linear fit within the limits of the standard deviation of the experimental wear data. These correlations are benchmarked with test conditions which are similar to those defined in ASTM G133 (Procedure A).

In general, to meet the challenge to spray hardmetal coatings with suspension, there is a need to develop tailored nanocomposite powders with small carbide grain size, with particle sizes which can formulate stable suspensions. Nanoparticles appearing in the as-sprayed coating can strengthen the binder phase and improve the dry sliding wear resistance. More detailed studies on the compositional and phase changes during spraying and heat treatment are required.

Acknowledgement The authors are grateful for the support of Dr Susan Davies at Bodycote HIP UK for the HIPing of S-HVOF coatings and Mr Björn Matthey of Fraunhofer IKTS for performing 
the Rietveld analysis. Financial support of Saudi-ARAMCO for this project is also greatly appreciated.

Open Access This article is distributed under the terms of the Creative Commons Attribution 4.0 International License (http://crea tivecommons.org/licenses/by/4.0/), which permits unrestricted use, distribution, and reproduction in any medium, provided you give appropriate credit to the original author(s) and the source, provide a link to the Creative Commons license, and indicate if changes were made.

\section{References}

1. Berger, L.-M.: In: Sarin, V., Mari, D., Llanes, L., Nebel, C. (eds.) Comprehensive Hard Materials, Hardmetals, 1st edn, pp. 471-506. Elsevier, Amsterdam (2014)

2. Shipway, P.H., McCartney, D.G., Sudaprasert, T.: Sliding wear behaviour of conventional and nanostructured HVOF sprayed WC-Co coatings. Wear 259(7-12), 820-827 (2005)

3. Yang, Q., Senda, T., Ohmori, A.: Effect of carbide grain sizeo nmicrostructure and sliding wear behavior of HVOF-sprayed WC-12\% Co coatings. Wear 254(1-2), 23-34 (2003)

4. Rajinikanth, V., Venkateswarlu, K.: An investigation of sliding wear behavior of WC-Co coating. Tribol. Int. 44(12), 1711-1719 (2011)

5. Wood, R.J.K.: Tribology of thermal sprayed WC-Co coatings. Int. J. Refract. Metals Hard Mater. 28(1), 82-94 (2010)

6. Engqvist, H., Högberg, H., Botton, G.A., Ederyd, S., Axén, N.: Tribofilm formation on cemented carbides in dry sliding conformal contact. Wear 239(2), 219-228 (2000)

7. Shipway, P.H., Hogg, J.J.: Dependence of microscale abrasion mechanisms of WC-Co hardmetals on abrasive type. Wear 259(1-6), 44-51 (2005)

8. Houdková, Š., Zahálka, F., Kašparová, M., Berger, L.-M.: Comparative study of thermally sprayed coatings under different types of wear conditions for hard chromium replacement. Tribol. Lett. 43(2), 139-154 (2011)

9. Bonache, V., Salvador, M.D., García, J.C., Sánchez, E., Bannier, E.: influence of plasma intensity on wear and erosion resistance of conventional and nano-metric WC-Co coatings deposited by APS. J. Therm. Spray Technol. 20(3), 549-559 (2011)

10. Sánchez, E., Bannier, E., Salvador, M.D., Bonache, V., García, J.C., Morgiel, J., Grzonka, J.: Microstructure and wear behavior of conventional and nanostructured plasma-sprayed WC-Co coatings. J. Therm. Spray Technol. 19(5), 964-974 (2010)

11. Bolelli, G., Cannillo, V., Lusvarghi, L., Rosa, R., Wanhuk, A.V., Choib, B., Dey, R., Weyant, C., Sampath, S.: Functionally graded WC-Co/NiAl HVOF coatings for damage tolerance, wear and corrosion protection. Surf. Coat. Technol. 206(8-9), 2585-2601 (2012)

12. Chen, H., Gou, G., Tu, M., Liu, Y.: Research on the friction and wear behavior at elevated temperature of plasma-sprayed nanostructured WC-Co coatings. J. Mater. Eng. Perform. 19(1), $1-6(2010)$

13. de Villiers Lovelock, H.-L.: Powder/processing/structure relationship in WC-Co thermal spray coatings: a review of the published literature. J. Therm. Spray Technol. 7(3), 357-373 (1998)

14. Stewart, S., Ahmed, R.: Contact fatigue failure modes in hot isostatically pressed WC $-12 \%$ Co coatings. Surf. Coat. Technol. 172(2-3), 204-216 (2003)

15. Stoica, V., Ahmed, R., Itsukaichi, T., Tobe, S.: Sliding wear evaluation of hot isostatically pressed (HIPed) thermal spray cermet coatings. Wear 257(11), 1103-1124 (2004)
16. Stewart, S., Ahmed, R., Itsukaichi, T.: Rolling contact fatigue of post-treated WC-NiCrBSi thermal spray coatings. Surf. Coat. Technol. 190(2-3), 171-189 (2005)

17. Ahmed, R., Hadfield, M.: Mechanisms of fatigue failure in thermal spray coatings. J. Therm. Spray Technol. 11(3), 333-349 (2002)

18. Vuoristo, P., Niemi, K., Mäntylä, T., Berger, L.-M., Nebelung, M.: Comparison of different hardmetal-like coatings sprayed by plasma and detonation gun processes, advanced thermal spray science technology. In: Berndt, C.C., Sampath S. (eds.) Proceedings of the 8th National Thermal Spray Conference, pp. 309-315, 11-15 September 1995, ASM International, Materials Park, Houston (1995)

19. Fauchais, P., Montavon, G., Lima, R.S., Marple, B.R.: Engineering a new class of thermal spray nano-based microstructures from agglomerated nanostructured particles, suspension and solutions: an invited review. J. Phys. D Appl. Phys. 44, 53 (2011). artno.093001

20. Chawla, V., Sidhu, B.S., Puri, D., Prakash, S.: State of art: plasma sprayed nanostructured coatings: a review. Mater. Forum 32, 137-143 (2008)

21. He, J., Schoenung, J.M.: Nanostructured coatings. Mater. Sci. Eng. A 336(1-2), 274-319 (2002)

22. Ahmed, R., Ali, O., Faisal, N.H., Al-Anazi, N.M., Al-Mutairi, S., Toma, F.-L., Berger, L.-M., Potthoff, A., Goosen, M.F.A.: Sliding wear investigation of suspension sprayed WC-Co nanocomposite coatings. Wear 322-323, 133-150 (2015)

23. Ahmed, R., Faisal, N.H., Al-Anazi, N.M., Al-Mutairi, S., Toma, F.-L., Berger, L.-M., Potthoff, A., Polychroniadis, E.K., Sall, M., Chaliampalias, D., Goosen, M.F.A.: Structure property relationship of suspension thermally sprayed WC-Co nanocomposite coatings. J. Therm. Spray Technol. 24(3), 357-377 (2015)

24. Oberste Berghaus, J., Marple, B., Moreau, C.: Suspension Plasma Spraying of Nanostructured WC-12Co Coatings. J. Therm. Spray Technol. 15(4), 676-681 (2006)

25. Thiele, S., Sempf, K., Jaenicke-Roessler, K., Berger, L.-M., Spatzier, J.: Thermophysical and microstructural studies on thermally sprayed tungsten carbide-cobalt coatings. J. Therm. Spray Technol. 20(1-2), 358-365 (2011)

26. Mari, D., Berger, L.-M., Stahr, S.: Analysis of microstructural changes with temperature of thermally sprayed WC-Co coatings by mechanical spectroscopy. Solid State Phenom. 184, 313-318 (2012)

27. Nerz, J., Kushner, B., Rotolico, A.: Microstructural evaluation of tungsten carbide-cobalt coatings. J. Therm. Spray Technol. 1(2), 147-152 (1992)

28. Li, C.-J., Ohmori, A., Harada, Y.: Formation of an amorphous phase in thermally sprayed WC-Co. J. Therm. Spray Technol. 5(1), 69-73 (1996)

29. Schwetzke, R., Kreye, H.: Microstructure and properties of tungsten carbide coatings sprayed with various high-velocity oxygen fuel spray systems. J. Therm. Spray Technol. 8(3), 433-439 (1999)

30. Stewart, D.A., Shipway, P.H., McCartney, D.G.: Influence of heat treatment on the abrasive wear behaviour of HVOF sprayed WCCo coatings. Surf. Coat. Technol. 105(1-2), 13-24 (1998)

31. Lima, M.M., Godoy, C., Avelar-Batista, J.C., Modenesi, P.J.: Toughness evaluation of HVOF WC-Co coatings using non-linear regression analysis. Mater. Sci. Eng. A 357(1-2), 337-345 (2003)

32. Stoica, V., Ahmed, R.: Influence of heat treatment on sliding wear of thermal spray cermet coatings. Surf. Coat. Technol. 199(1), 7-21 (2005)

33. Stoica, V., Ahmed, R., Tobe, S.: Sliding wear evaluation of hot isostatically pressed thermal spray ceramet coatings. J. Therm. Spray Technol. 13(1), 93-107 (2004) 
34. Ahmed, R., Yu, H., Stewart, S., Edwards, L., Santisteban, J.R.: Residual strain measurements in thermal spray cermet coatings via neutron diffraction. J. Tribol. 129(2), 411-418 (2007)

35. Ahmed, R., Fitzpatrick, M.E., Faisal, N.H.: A comparison of neutron diffraction and hole-drilling residual strain measurements in thermally sprayed coatings. Surf. Coat. Technol. 206(19), 4180-4185 (2012)

36. Berger, L.-M., Saaro, S., Woydt, M.: Reib-/Gleitverschleiß von thermisch gespritzten Hartmetallschichten. In: Suchentrunk, R. (ed.) Jahrbuch Oberflächentechnik 2007, vol. 63, pp. 242-267. Eugen G. Leuze Verlag, Bad Saulgau (2007)

37. Berger, L.-M., Woydt, M., Saaro, S.: Comparison of self-mated hardmetal coatings under dry sliding conditions up to $600{ }^{\circ} \mathrm{C}$. Wear 266(3-4), 406-416 (2009)

38. Faisal, N.H., Steel, J.A., Ahmed, R., Reuben, R.L.: The use of acoustic emission to characterize fracture behavior during Vickers indentation of HVOF thermally sprayed WC-Co coatings. J. Therm. Spray Technol. 18(4), 525-535 (2009)

39. Faisal, N.H., Ahmed, R., Prathuru, A.K., Spence, S., Hussain, M., Steel, J.A.: An improved vickers indentation fracture toughness model to assess the quality of thermally sprayed coatings. Eng. Fract. Mech. 128, 189-204 (2014)

40. Oliver, W.C., Pharr, G.M.: An improved technique for determining hardness and elastic modulus using load and displacement sensing indentation experiments. J. Mater. Res. 7, 1564-1583 (1992)

41. Li, C.-J., Yang, G.-J.: Relationships between feedstock structure, particle parameter, coating deposition, microstructure and properties for thermally sprayed conventional and nanostructured WC-Co. Int. J. Refract. Met. Hard Mater. 39, 2-17 (2013)

42. Verdon, C., Karimi, A., Martin, J.-L.: A study of high velocity oxy-fuel thermally sprayed tungsten carbide based coatings. Part 1: microstructures. Mater. Sci. Eng. A246(1-2), 11-24 (1998)
43. Stewart, D.A., Shipway, P.H., McCartney, D.G.: Microstructural evolution in thermally sprayed WC-Co coatings: comparison between nanocomposite and conventional starting powders. Acta Mater. 48(7), 1593-1604 (2000)

44. Kurlov, A.S., Gusev, A.I.: Tungsten Carbides and W-C phase diagram, Neorganicheskie Materialy, 2006, 42(2), pp. 156-163, in Russian [Inorganic Materials, 2006, 42(2), p 121-127, in English]

45. Dante, R.C., Kajdas, C.K.: A review and a fundamental theory of silicon nitride tribochemistry. Wear 288, 27-38 (2012)

46. Bolelli, G., Berger, L.-M., Börner, T., Koivuluoto, H., Lusvarghi, L., Lyphout, C., Markocsan, N., Matikainen, V., Nylén, P., Sassatelli, P., Trache, R., Vuoristo, P.: Tribology of HVOF- and HVAF-sprayed WC 10Co4Cr hardmetal coatings: a comparative assessment. Surf. Coat. Technol. 265, 125-144 (2015)

47. Guilemany, J.M., Miguel, J.M., Vizcaino, S., Climent, F.: Role of three-body abrasion wear in the sliding wear behaviour of WCCo coatings obtained by thermal spraying. Surf. Coat. Technol. 140(2), 141-146 (2001)

48. Wayne, S.F., Baldoni, J.G., Buljan, S.T.: Abrasion and erosion of WC-Co with controlled microstructures. Tribol. Trans. 33(4), 611-617 (1990)

49. Ahmed, R., Ashraf, M.A., Elameen, M., Faisal, N.H., El-Sherik, A.M., Elakwah, Y.O., Goosen, M.F.A.: Single asperity nanoscratch behavior of HIPed and Cast Stellite 6 alloys. Wear 312(1-2), 70-82 (2014)

50. Faisal, N.H., Ahmed, R., Reuben, R.L.: Indentation testing and its acoustic emission response: applications and emerging trends. Int. Mater. Rev. 56(2), 98-142 (2011)

51. Ashraf, M.A., Ahmed, R., Ali, O., Faisal, N.H., El-Sherik, A.M., Goosen, M.F.A.: Finite element modeling of sliding wear in a composite alloy using a free-mesh. J. Tribol. (2015). doi:10.1115/ 1.4029998 